\title{
The composition of cuticular compounds indicates body parts, sex and age in the model butterfly Bicyclus anynana (Lepidoptera)
}

\section{Stéphanie Heuskin ${ }^{1,2 *}$, Maryse Vanderplanck ${ }^{3}$, Paul Bacquet ${ }^{1}$, Marie-Jeanne Holveck ${ }^{1}$, Martin Kaltenpoth ${ }^{4}$, Tobias Engl ${ }^{4}$, Christophe Pels ${ }^{1}$, Cédric Taverne ${ }^{5}$, Georges Lognay ${ }^{2}$ and Caroline M. Nieberding ${ }^{1}$}

\author{
' Group of Evolutionary Ecology and Genetics, Biodiversity Research Centre, Earth and Life Institute, Université catholique de Louvain, Louvain-la-Neuve, Belgium \\ ${ }^{2}$ Laboratory of Analytical Chemistry, Gembloux Agro-Bio Tech, University of Liege, Gembloux, Belgium \\ ${ }^{3}$ Laboratory of Zoology, University of Mons, Mons, Belgium \\ 4 Insect Symbiosis Research Group, Max Planck Institute for Chemical Ecology, Jena, Germany \\ ${ }^{5}$ Institut de Statistique, Biostatistique et Sciences Actuarielles, Université catholique de Louvain, Louvain-la-Neuve, Belgium
}

\section{Edited by:}

Emmanuelle Jacquin-Joly, Institut

National de la Recherche

Agronomique, France

Reviewed by:

Wynand Van Der Goes Van Naters,

Cardiff University, UK

Thomas Seth Davis, University of Idaho, USA

Jeremy N. McNeil, The University of

Western Ontario, Canada

\section{*Correspondence:}

Stéphanie Heuskin, Laboratory of

Analytical Chemistry, Gembloux

Agro-Bio Tech, University of Liege,

Passage des Déportés 2,

B-5030 Gembloux, Belgium

e-mail:Stephanie.heuskin@ulg.ac.be
Chemical communication in insects' sexual interactions is well-known to involve olfaction of volatile compounds called sex pheromones. In theory, sexual chemical communication may also involve chemicals with low or no volatility exchanged during precopulatory gustatory contacts. Yet, knowledge on this latter type of chemicals is so far mostly restricted to the Drosophila fly model. Here we provide the most comprehensive characterization to date of the cuticular chemical profile, including both volatile and non-volatile compounds, of a model butterfly, Bicyclus anynana. First, we characterized the body distribution of 103 cuticular lipids, mostly alkanes and methyl-branched alkanes, by gas chromatography coupled to mass spectrometry (GC-MS). Second, we developed a multivariate statistical approach to cope with such complex chemical profiles and showed that variation in the presence or abundance of a subset of the cuticular lipids indicated body parts, and traits involved in $B$. anynana mate choice, namely sex and age. Third, we identified the chemical structure of the 20 most indicative compounds, which were on average more abundant (1346.4 $\pm 1994.6 \mathrm{ng}$; mean $\pm S D$ ) than other, likely less indicative, compounds $(225.9 \pm 507.2 \mathrm{ng}$; mean $\pm S D$ ). Fourth, we showed that wings and legs displayed most of the chemical information found on the entire body of the butterflies. Fifth, we showed that non-random gustatory contacts occurred between specific male and female body parts during courtship. The body parts mostly touched by the conspecific displayed the largest between-sex differentiation in cuticular composition. Altogether, the large diversity of cuticular lipids in B. anynana, which exceeds the one of Drosophila flies, and its non-random distribution and evaluation across individuals, together suggest that gustatory information is likely exchanged during sexual interactions in Lepidoptera.

Keywords: cuticular lipids, chemical communication, gustation, butterfly, age, sex

\section{INTRODUCTION}

Chemical communication, including both olfaction and taste, is common in most living organisms but remains understudied compared to other modes of communication such as vision and audition (Wyatt, 2003, 2009). Chemical communication is based on combinations of chemical compounds that provide the potential to transfer sophisticated information about individuals, as documented in some vertebrates (Brennan and Zufall, 2006), and in social invertebrates (Moore et al., 1997; Thom et al., 2007; Guerrieri et al., 2009). For example, over a thousand cuticular hydrocarbons were identified in around eighty species of ants (Martin and Drijfhout, 2009), and efficient discrimination between "friends" (nest-mates) and "foes" (non-nest-mates) is based on the presence of specific cuticular hydrocarbons (Guerrieri et al., 2009). Social parasites of ants such as the caterpillars of Maculinea butterflies have cracked their host's chemical code using chemical camouflage and mimicry to access the ant nest (Nash et al., 2008). Refined information can thus be transferred among individuals, which reflects the complexity of the social interactions observed at intraspecific and interspecific levels.

Chemical signals should also convey a wide diversity of information regarding the quality or identity of potential mating partners encompassing both intraspecific (assessment of mate quality) and interspecific (species recognition) interactions (Andersson, 1994; Wyatt, 2003; Johansson and Jones, 2007). In this regard, sex pheromones are chemicals used for intraspecific communication between potential mating partners. Pioneering 
work in Drosophila fruit flies revealed that both olfactory and gustatory communications are of primary importance for mate choice. Fruit flies rely on the presence of the volatile cis-vaccenyl acetate (cVA) and on several abundant, sex-specific cuticular hydrocarbons of low volatility for deciphering species, strain, sex, mating status, and for eliciting between-sexes courtships as well as inhibiting same-sex courtships (Cobb and Jallon, 1990; Greenspan and Ferveur, 2000; Ferveur and Cobb, 2010). While cVA is sensed through olfactory neurons (Kurtovic et al., 2007), it was recently demonstrated that the cuticular hydrocarbons are detected by contact using chemosensitive receptors and are necessary to initiate courtship (Thistle et al., 2012). Thus, non-social species also exchange refined information using chemical signals, and both volatile and non-volatile compounds such as cuticular hydrocarbons may be essential for mate choice.

Although courtship in insects often involves precopulatory inter-individual contacts as it is known in Drosophila (Hall, 1994), providing room for close range olfactory and gustatory assessments of mate quality (Bonduriansky, 2001), the role of cuticular hydrocarbons, and other cuticular lipids with low volatility, remains poorly studied for mate choice in species other than Drosophila and some Diptera, Coleoptera, and Orthoptera species (Tregenza and Wedell, 1997; Rantala et al., 2002, 2003; Rantala and Kortet, 2004; Kortet and Hedrick, 2005; Thomas and Simmons, 2009; Ginzel, 2010). This is particularly surprising in Lepidoptera, as this insect order includes several model organisms in chemical communication for mate choice and sexual selection using volatile sex pheromones produced by females to attract males from a long distance (Svensson, 1996; Millar, 2000; Ando, 2004; Johansson and Jones, 2007; Millar et al., 2010). Males of some species of moths and of butterflies also produce volatile sex pheromones but their study has received much less attention. Partial behavioral and chemical analyses of such male sex pheromones (MSP) have been made for some species of moth (Baker et al., 1981; Nishida et al., 1982; Phelan et al., 1986; Teal and Tumlinson, 1989; Dussourd et al., 1991; Jacquin et al., 1991; Heat et al., 1992; Thibout et al., 1994; Kimura and Honda, 1999; Iyengar et al., 2001; Sasaerila et al., 2003; Hillier and Vickers, 2004; Landolt et al., 2004; Monteys et al., 2012) and a few species of butterfly (Pliske and Eisner, 1969; Taylor, 1973; Grula et al., 1980; Sappington and Taylor, 1990a,b,c; Nishida et al., 1996; Andersson et al., 2007; Nieberding et al., 2008, 2012). MSPs are usually employed at short-range during the courtship sequence (Myers, 1972; Birch et al., 1990; VaneWright and Boppre, 1993) and are associated with scent-releasing organs called coremata or androconia found on the legs, wings, thorax, or abdomen (Birch et al., 1990). Male olfactory displays in Lepidoptera are thought to be involved in mate assessment where they can convey information about the prospective mates (Mustaparta, 1996; Costanzo and Monteiro, 2007), such as quality and quantity of nuptial gifts (Dussourd et al., 1991), or male size (Iyengar et al., 2001) (but see Kemp et al., 2008; Nieberding et al., 2008), though experimental demonstration of the role of hair-pencils and other organs associated with the release of MSP remains scarce (Davie et al., 2010). In addition, Lepidoptera also produce cuticular lipids with no or low volatility, but their role in mate choice and sexual selection remains barely understood. This is partly due to the difficulty in identifying behaviorally and physiologically active compounds when these have low or no volatility. To date, a partial analysis of the cuticular compounds was undertaken in eight moth species [Cydia pomonella (Piskorski et al., 2010), Conogethes punctiferalis (Xiao et al., 2012), Orgyia leucostigma (Grant et al., 1987), Lymantria dispar (Jurenka and Subchev, 2000), Helicoverpa zea, Heliothis virescens, Manduca sexta (Carlson and Milstrey, 1991; Böröczky et al., 2008), Anticarsia gemmatalis (Heath et al., 1983)] and in eight butterfly species [Colias eurytheme (Grula et al., 1980; Sappington and Taylor, 1990c), Idea leucone (Nishida et al., 1996; Schulz and Nishida, 1996), Pieris rapae (Arsene et al., 2002), Papilio polytes (Ômura and Honda, 2005), two species in the Danaus genus (Hay-Roe et al., 2007) and two species in the Lasiommata genus (Dapporto, 2007)]. It was shown that some of these compounds act as MSP (Sappington and Taylor, 1990c; Schulz and Nishida, 1996) or play a key role in reproductive isolation between closely related species (Grula et al., 1980), but the structure or the function of the large majority of the chemicals found on the cuticle of Lepidoptera remains so far uncharacterized.

Against this background, we herein provide the characterization of compounds up to 40 carbon atoms of the cuticular profile of the model butterfly Bicyclus anynana. The tropical sub-Saharan butterfly genus Bicyclus (Bush Browns; Lepidoptera, Satyrinae) includes over 80 species that are poorly differentiated morphologically and up to 20 species can be found in sympatry in a single forest patch (Condamin, 1973). The main morphological character used to discriminate species is the position and shape of the androconia, which are male wing patches and brushes formed by modified scales and thought to produce the MSP components (Condamin, 1973). Large chemical, but limited morphological, divergence together suggest that chemical profiles are used for species recognition in this group of butterflies, and may be involved in Bicyclus speciation (Bacquet et al., in revision). In the model species B. anynana (Butler, 1879; Brakefield et al., 2009), we have now extensive physiological (Nieberding et al., 2008), behavioral (Costanzo and Monteiro, 2007; Nieberding et al., 2008, 2012; Van Bergen et al., 2013; Westerman and Monteiro, 2013), comparative (Bacquet et al., in revision)., quantitative genetics (Nieberding et al., 2012) and biosynthetic (Liénard et al., 2014) evidence of the function and the selective forces acting on the volatile sex pheromone. Females rely for mate choice on the perception of three volatile male-specific wing components forming the male sex pheromone, namely (Z)-9-tetradecenol (MSP1 hereafter), hexadecanal (MSP2), and 6,10,14-trimethylpentadecan2-ol (MSP3) (Costanzo and Monteiro, 2007; Nieberding et al., 2008). The MSP composition enables females to finely assess age and inbreeding differences between courting males (Nieberding et al., 2012; Van Bergen et al., 2013). MSP composition also mediates learning of visual signals implicated in mate choice in B. anynana (Westerman and Monteiro, 2013). Yet, chemical communication in this species is likely not limited to the information conveyed by MSP composition for the following two reasons. First, male and female cuticles likely display, as in other insects, a much larger number of compounds but the majority have low volatility and as such could not be previously detected by gaschromatography coupled to electro-antennograms (GC-EAD; 
Nieberding et al., 2008). Second, B. anynana courtship as observed by ultrafast camera images (Nieberding et al., 2008) might be close to Drosophila melanogaster's one in the way that a male and a female touch specific parts of each other body with their antennae, proboscis, legs and abdominal tip (Hall, 1994). As olfactory receptors are found in the fly antennae while receptors for cuticular lipids are found in the fly antennae, legs and proboscis (Amrein and Thorne, 2005; Ebbs and Amrein, 2007; Miyamoto and Amrein, 2008; Thistle et al., 2012), it suggests that different body parts may convey specific pieces of information using chemicals of different structure and volatility. We herein provide the most complete description of compounds present on the cuticular surface of a butterfly to date, including the structural identification for the most abundant compounds, and their quantification. On the basis of courting interactions between individuals, we hypothesized that the distribution of cuticular lipids and the location of gustatory contacts between sexes may not be random and may inform about some aspects of quality of the potential mate in B. anynana. In particular, we predicted that: (i) the composition in cuticular lipids across different body parts may be indicative of sex and age, and that (ii) the gustatory contacts, if involved in mate choice, should preferentially occur between body parts showing a sex-specific composition.

\section{MATERIALS AND METHODS INSECTS REARING}

An outbred laboratory stock of the African butterfly, B. anynana, was established in 1988 from over 80 gravid females collected in a single source population in Malawi and maintained at a large population size (Brakefield and Reitsma, 1991). The genetic diversity was maintained at a level similar to the one of the original population (Brakefield et al., 2009). The experiments were performed on the wet, reproductive, seasonal form: larvae were reared in a climate room under a standard temperature regime $\left(27^{\circ} \mathrm{C}\right), 12: 12 \mathrm{~L}: \mathrm{D}$ regime and high relative humidity $(80 \%)$, while adults were subject to the following day-night range of temperature and humidity: $22-27^{\circ} \mathrm{C}$ and $50-60 \%$ humidity. Larvae and adults were fed ad libitum on maize Zea maïs, and banana Musa acuminate, respectively. Individuals of different sexes or ages were kept apart within $12 \mathrm{~h}$ after emergence in different cylindrical hanging netted cages (diameter $30 \mathrm{~cm}$, height $38 \mathrm{~cm}$ ) at a maximum density of 15 adults per cage.

\section{ANALYSIS OF CUTICULAR LIPIDS COMPOSITION Acquisition of cuticular samples}

Virgin male and female butterflies were sampled at the following age classes: 1, 3, 8, 14, and 21-days old. All butterflies were killed $7 \mathrm{~h}$ after lights were switched on (at 10:00 am) by placing them in individual envelopes at $-80^{\circ} \mathrm{C}$. For the GC-MS analyses, three to six individuals were sampled per category (two sexes and five age classes; $n=10$ categories). The antennae, wings and legs of each individual were carefully cut using cleaned fine scissors, while their abdomen and head were not cut to avoid the contamination of the extract by hemolymph. The head was first soaked in n-hexane then the body of the butterfly was turned over in another vial with n-hexane (VWR, Leuven, Belgium) to soak abdomen. All body parts were separately soaked in a precise volume of $\mathrm{n}$-hexane $(50 \mu \mathrm{L}$ for antennae and legs, $270 \mu \mathrm{L}$ for abdomen and head, $300 \mu \mathrm{L}$ for wings) for 5 (all body parts but wings) or 10 (wings) $\min (n=210 \mathrm{n}$-hexane extracts in total for GC-MS analyses). Next, gas chromatography coupled to a flame ionization detector (GC-FID) analyses were carried out in order to increase the sample size of our dataset and hence validate the robustness of our statistical analyses based on GC-MS dataset. For the GC-FID analyses, we sampled 3-18 individuals per category and only extracted the legs and wings simultaneously in the same vial (see results' section Validation of the list of indicative compounds by GC-FID) using $350 \mu \mathrm{L}$ of n-hexane with internal standard at $15 \mathrm{ng} / \mu \mathrm{L}$ for $10 \mathrm{~min}(n=106$ extracts in total). The other butterfly parts were not extracted for GC-FID analyses. The extracts were filtered using glass Pasteur pipettes fitted with a small piece of glass wool $(15 \mathrm{mg})$ to remove the scales from the samples prior to GC-MS and GC-FID analyses. Blanks of nhexane were sampled after extraction of every three individuals to check the absence of contamination in the solvent used during the extraction procedure.

\section{Gas chromatography coupled to mass spectrometry (GC-MS) analyses 1}

Conventional GC-MS analyses were carried out on a Thermo Trace GC Ultra coupled with a Thermo Trace MS Finnigan mass selective detector (Thermo Electron Corp., Interscience, Louvain-la-Neuve, Belgium) and equipped with an Optima-5Accent (Macherey-Nagel, Düren, Germany) capillary column (30 $\mathrm{m} \times 0.25 \mathrm{~mm}$ I.D., $0.25 \mu \mathrm{m}$ film thickness). The oven temperature program was initiated at $40^{\circ} \mathrm{C}$ held for $2 \mathrm{~min}$ then raised at $10^{\circ} \mathrm{C} / \mathrm{min}$ to $320^{\circ} \mathrm{C}$ and held at this final temperature for $10 \mathrm{~min}$. Carrier gas was Helium at a constant flow rate of $1.5 \mathrm{~mL} / \mathrm{min}$. Injection volume was $1 \mu \mathrm{L}$ in splitless mode (splitless time: $0.80 \mathrm{~min}$ ). The temperature of the injector was fixed at $300^{\circ} \mathrm{C}$. The temperature of the interface between GC and MS was fixed at $320^{\circ} \mathrm{C}$. MS detection was performed in the electron impact (EI) mode at $70 \mathrm{eV}$ by operating with the full-scan acquisition mode in the 30-500 amu mass range. The identification of the natural compounds was performed by comparing the obtained mass spectra fragmentation patterns with those from the Nist spectral library and by comparing their retention indices to literature data (Pherobase data) and Nist data. Retention indices $\left(I_{i}\right)$ were determined relative to the retention times of two mixes of $n$-alkane standards (C7-C30 at $10 \mathrm{ng} / \mu \mathrm{L}$ in $\mathrm{n}$-hexane, Sigma, Bornem, Belgium; and C9-C40 at $50 \mathrm{ng} / \mu \mathrm{L}$ in n-hexane, Dr. Ehrenstorfer, Augsburg, Germany) measured under the chromatographic conditions described above. Quantification of compounds (in ng) was established by external standardization by comparing the area of each peak to the mean area of C7-C30 reference alkanes at $10 \mathrm{ng} / \mu \mathrm{L}$ injected in GC-MS [10 replicates, Relative Standard Deviation (RSD) of manual injection repeatability $=4.4 \%$ : this value is lower than the maximal acceptable limit of $12 \%$, according to the AOAC norm (2006), to consider that the method is validated]. External standardization was preferred in GC-MS analyses instead of internal standard quantification because prior to commencing our experiment we had no idea of the nature of cuticular compounds of the butterflies precluding the selection of an appropriate internal standard. 


\section{GC-MS analyses 2}

Complementary identification of the most abundant hydrocarbons was performed using a subset of the cuticular extracts analyzed by the first GC-MS analyses, by a comparison of their MS fragmentation patterns and retention times with a mix of $n$ alkane standards (C7-C30) (Fluka, Germany). The GC-MS analysis was performed using a Varian 240 MS quadrupole ion-trap mass detector coupled to a Varian 450 GC (QIT GC-MS) (Kroiss et al., 2011). All analyses were performed in the external ionization configuration. A DB-5 ms column (Agilent Technologies, Böblingen, Germany; $30 \mathrm{~m} \times 0.25 \mathrm{~mm}$ i.d. $\times 0.25 \mu \mathrm{m}$ film) was used to separate the hydrocarbons. The temperature of the split/splitless GC injector was set to $250^{\circ} \mathrm{C}$, and the injector was operated in the splitless mode. The GC oven temperature was programmed as follows: $150^{\circ} \mathrm{C}$ for $1 \mathrm{~min}, 5^{\circ} \mathrm{C} / \mathrm{min}$ to $300^{\circ} \mathrm{C}$ and a hold for $5 \mathrm{~min}$. Helium was used as the carrier gas at a constant flow rate of $1 \mathrm{~mL} / \mathrm{min}$.

\section{Gas chromatography coupled to a flame ionization detector (GC-FID) analyses}

GC-FID analyses were performed on a Thermo Trace GC Ultra gas chromatograph equipped with a flame ionization detector and an AS 3000 autosampler (Thermo Scientific, Interscience, Louvain-la-Neuve, Belgium). The capillary column, the temperature program, the injection conditions and the carrier gas at constant flow of $1.5 \mathrm{~mL} / \mathrm{min}$ were the same than in GC-MS analyses 1. Detection was performed with $300 \mathrm{~Hz}$ FID detector at $310^{\circ} \mathrm{C}$. The flame composition of the detector was: $350 \mathrm{~mL} / \mathrm{min}$ air, $35 \mathrm{~mL} / \mathrm{min}$ hydrogen, $30 \mathrm{~mL} / \mathrm{min}$ nitrogen (makeup gas). Identification of cuticular compounds was done by comparing their retention indices (calculated with a mix of n-alkanes, see GC-MS analyses 1) to those of GC-MS analyses 1. Quantification was achieved by means of internal standard, palmityl acetate (Sigma, Bornem, Belgium) at $15 \mathrm{ng} / \mu \mathrm{L}$ in $\mathrm{n}$-hexane (as extraction solvent).

\section{STATISTICAL ANALYSES OF CUTICULAR LIPIDS COMPOSITION Statistics on the GC-MS and GC-FID datasets}

The GC-MS dataset consisted of 210 cuticular extracts sampled for three qualitative factors-sex (two levels, fixed), age (five levels, fixed) and body parts (five levels, fixed) - with three to six replicates per group (a group is characterized by one sex, one age, and one body part), and of 103 quantitative variables formed by the cuticular compounds. The GC-FID dataset consisted of cuticular extracts sampled for two qualitative factors, sex (two levels, fixed) and age (five levels, fixed), with three to 18 replicates per group ( $n=106$ analyses in total), and of 57 quantitative variables (cuticular compounds). We used either each cuticular extract independently or we pooled all body parts of each insect ("complete individuals" hereafter) for the following statistical tests. All analyses described here under were performed using the GCMS dataset, and we conducted the perMANOVA analysis, the indicative compound analysis (ICA) and the nMDS ordination on the GC-FID dataset as well in order to determine differences of composition in cuticular compound profiles for sexes and ages.

First, to assess the repeatability of the compounds, nonparametric Spearman rank correlations were performed between compounds within factors (sex, age, body parts) across individuals. Second, we performed a cluster analysis to characterize the overall distribution of the absolute abundances of the 103 cuticular compounds according to sex, age, or body parts. We used the Ward hierarchical algorithm (Ward, 1963) consolidated by a maximum of $10 \mathrm{~K}$-means iterations (Lloyd, 1982). The clustering was performed on the whole axes of a principal component analysis (PCA) in order to allow the use of Euclidean distance in K-means. The $\mathrm{R}$ function HCPC was used. The number of relevant clusters (three large and four small groups) was fixed by the major break in the inertia gain barplot. We tested the stability of the clusters without the four small groups and it showed very stable association measures with the three factors of interest. Independence chi-squared tests were used to assess the significance of the clustering.

Third, we assessed whether there were significant differences in cuticular lipids composition among factors and identified which cuticular compound was indicative of each factor. Permutational multivariate analyses of variance (perMANOVA) were performed using the Bray-Curtis similarity matrix and 999 permutations (Anderson, 2001; McArdle and Anderson, 2001). It is a permutation-based version of the multivariate analysis of variance (MANOVA) (Anderson, 2005). Like conventional analyses of variances, the perMANOVA calculates a F-statistic by taking the ratio of "among-group sums of squares" to "within-group sums of squares," and produces a $p$-value used to detect significant differences in the abundance and composition of cuticular lipids across samples. As it is a permutational test, the perMANOVA does not depend on: (i) the correlation between variables, (ii) the presence of some null data in the dataset, and (iii) the multinormality of groups (the different levels of the qualitative factor considered) (Anderson, 2005). Next, an ICA was conducted to identify which compounds are indicative of age, sex or body part. Of note, the ICA is similar to better-known "Indicator Species Analysis" (Indval), which is usually used with species data but is here applied to chemical data. This analysis calculates the probability that a compound is found in association with one factor. An indicator value, which is function of the relative abundance and frequency of a compound, was calculated for each cuticular compound and allowed to identify the factor with the highest indicator value for each compound. All indicator analyses were performed in R using the indval function from the labdsv package.

Fourth, we performed non-metric multi-dimensional scaling (nMDS) ordinations to visually assess compositional differences in cuticular compounds. For this we used the R functions ecodist, ellipse (based on standard deviation with a confident interval of 0.95) and BiodiversityR. All nMDS plots were generated employing a Bray-Curtis similarity matrix, two dimensions (applying a conventional cutoff of $<0.2$ for the stress value) and 50 runs to fully explore the ordination space at that dimensionality. The minimum stress solution from this was used to produce the nMDS plots in which each spatial distance between samples can be interpreted as the relative difference in chemical composition.

Finally, we assessed how similar the chemical profiles obtained either by GC-MS or by GC-FID methodologies are. For this, we calculated the Spearman-rank correlations for the abundance of each chemical compound between pairs of individuals sampled 
either by GC-MS or by GC-FID (each sex and age categories separately). We used the 57 chemical compounds found in both GC-MS and GC-FID analyses and present in the wing and leg extracts performed for both GC-MS and GC-FID. We also estimated the correlation of the chemical profiles between individuals (age and sex factors separately) sampled using the same methodology (either both by GC-MS, or both by GC-FID). This allows us to distinguish whether the variation in abundance between the quantities of each compound across samples is due to the used methodology (GC-MS vs. GC-FID) or is due to biological diversity, as different individuals were used for each sample (MS-MS comparison, and FID-FID comparison). All statistical analyses were performed using R (2.14.0 version, at http://www. cran.org/).

\section{BEHAVIORAL ASSESSMENT OF GUSTATORY CONTACTS BETWEEN SEXES DURING COURTSHIP INTERACTIONS}

Previously published observations using high speed camera images revealed that males touch females during courtship, providing room for gustatory assessment of potential mating partners in this species (Nieberding et al., 2008). Here, we designed two behavioral experiments to assess where males and females taste each other during courtship interactions and to test the biological relevance of these contacts. Specifically, we predicted that the gustatory contacts between sexes should not be random but linked with sex differences in the cuticular composition between specific body parts. We made use of fluorescent dust powders to track and characterize the contacts that occur between sexes specifically during courtship interactions (Joron and Brakefield, 2003) and that are too quick for direct eye observations (Nieberding et al., 2008). As chemical receptors are known to be present on antennae and legs of insects, we dusted either the two antennae (Experiment 1) or the four legs (Experiment 2) of ca. 1-month old males and ca. 10-day old virgin females with colored "rodent-tracking" fluorescent dust (colors red "TP10" and chartreuse "TP35" Radiant Color, Belgium). We ran two replicates for each experiment. We dusted both sexes with a different color (yellow or red) per replicate and reversed colors between replicates. In a large cage $(120 \times 59 \times 60 \mathrm{~cm})$ filled with moist banana ad libitum and two maize plants allowing females to escape unwanted mating attempts by disappearing from male visual range, we released for each replicate 10 dusted males $1-3 \mathrm{~h}$ after day light was switched on, and then released 10 dusted females $1 \mathrm{~h}$ later. We collected all butterflies $24 \mathrm{~h}$ after the females had been released and inspected males and females under ultraviolet illumination to assess the transfer of fluorescent dust between sexes on the following body parts: head (including antennae and proboscis), thorax, abdomen, legs, and wings.

\section{RESULTS}

\section{LARGE DIVERSITY AND DIFFERENTIATION OF CUTICULAR LIPIDS ACROSS BODY PARTS}

To gain information on the spatial distribution of the chemical compounds potentially involved in courtship and mating behavior sequences of $B$. anynana butterflies, we first analyzed and quantified independently by GC-MS the cuticular composition of separated body parts (head, abdomen-thorax, legs, wings and antennae) of $42 \mathrm{~B}$. anynana individuals $(n=210$ samples, Supplement 1). We found 103 distinct compounds, of which the structure of the most abundant ones was determined (Supplement 2). Although our sampling was based on a limited number of individuals per group ( $n=$ three to six individuals per group; see Materials and Methods), the high repeatability of presence and abundance of compounds across GC-MS spectra supported that most indicative compounds for body parts, sex and age were identified in this study (average intra-category Spearman correlations between individuals is $r=0.73 \pm 0.13$, mean \pm SE; coefficient of determination $R^{2}=0.56 \pm 0.18$ ).

Alkanes and methyl-branched alkanes formed the majority of cuticular compounds, both in terms of number of components (19 and 11 identified alkanes and methyl-branched alkanes, respectively) and in terms of proportions [41.7 $\pm 15.9 \%$ and $17.0 \pm 5.7 \%$ (mean $\pm S D$ ) per individual for alkanes and methylbranched alkanes, respectively]. No alkene was identified; other cuticular lipids found on B. anynana body parts were aldehydes, alcohols, ketones and acids (Table 1, Supplement 2). The differentiation of cuticular lipid composition was significantly associated with body parts, sex and age (Ward hierarchical clustering consolidated by some K-means iterations with chi-square test for body parts and age: $p<0.01$; chi-square test for age: $p<0.05)$.

The cuticular composition of each body part was significantly different (perMANOVA: $d f=206, \mathrm{~F}$ stats $=30.0, p<0.001$ ). Moreover, a number of cuticular compounds were found to be indicative of each body part, i.e., the abundance and the presence of these compounds contributed significantly to the discrimination between factor levels: six compounds for antennae, 11 for head, 18 for legs, 56 for wings and nine for abdomen-thorax, (ICA; Supplement 2).

Table 1 | Main chemical classes of cuticular compounds identified in $B$. anynana, with their mean percentage per individual.

\begin{tabular}{lcc}
\hline $\begin{array}{l}\text { Class of } \\
\text { compound }\end{array}$ & $\begin{array}{c}\text { Number of } \\
\text { compounds }\end{array}$ & $\begin{array}{c}\text { \% compound class } \\
\text { per individual } \\
\text { (Mean } \pm \text { SD) }\end{array}$ \\
\hline MAIN CHAIN LENGTH (NUMBER OF CARBON ATOMS) \\
C14-C19 & 29 & $23.4 \pm 22.3$ \\
C20-C24 & 14 & $3.4 \pm 1.9$ \\
C25-C29 & 9 & $14.8 \pm 9.0$ \\
C30-C34 & 9 & $11.5 \pm 4.2$ \\
C35-C39 & 5 & $22.9 \pm 7.5$ \\
>C40 & 1 & $10.1 \pm 5.4$ \\
CUTICULAR HYDROCARBONS & & \\
Alkanes & 19 & $41.7 \pm 15.9$ \\
Branched alkanes & 13 & $17.0 \pm 5.7$ \\
MAIN FUNCTIONAL GROUPS & & $20.3 \pm 19.7$ \\
Alcohols & 6 & $4.5 \pm 3.1$ \\
Aldehydes & 11 & $0.9 \pm 0.9$ \\
Ketones & 1 & $1.7 \pm 2.0$ \\
Acids & 3 & $0.05 \pm 0.1$ \\
Others & 3 & $14.7 \pm 6.5$ \\
Unidentified compounds & 47 &
\end{tabular}




\section{CUTICULAR LIPID COMPOSITION INDICATES SEX}

We have tested whether a difference in chemical profiles existed between sexes using the same dataset of 42 individuals as above (see GC-MS chromatogram in Supplement 3). The cuticular composition of complete butterflies (perMANOVA; $d f=40, \mathrm{~F}$ stats $=18.6, p<0.001$ ) and of each body part, but the antennae, differed significantly according to sex (perMANOVA for all parts but antennae: $d f=40, \mathrm{~F}$ stats $>9.4$; $p<0.001$; for antennae: $d f=40$, F stats $=1.4, p=0.23$; non-metric multi-dimensional scaling (nMDS); Figure 1). This held true when the three malespecific wing sex pheromone components (Supplement 2) were excluded from the multivariate analysis (perMANOVA on whole insects; $d f=40$, F stats $=6.4, p<0.001$ ).

We identified 29 male-indicative (including the three MSP components), and six female-indicative, compounds (ICA, Supplement 2). Males produced significantly more compounds $(58.3 \pm 16.2$ for males vs. $43.9 \pm 9.5$ for females; mean $\pm S D$; two-sample $t$-test: $p<0.005)$ and in significantly higher amounts as compared with females $(43.4 \pm 18.5 \mu \mathrm{g}$ for males and $25.5 \pm 12.5 \mu \mathrm{g}$ for females; mean $\pm S D$; two-sample $t$-test: $p<0.001)$.

We assessed whether the sampling of different body parts separately affected our finding of sex-specific compounds. For this, we compared the list of indicative peaks for sex when either (a) the complete individuals were used or (b) each body part was analyzed independently. We found that 27 of the 29 maleindicative compounds and all six female-indicative compounds were present in wings and legs (Supplement 2).

\section{CUTICULAR LIPID COMPOSITION INDICATES AGE}

From the GC-MS dataset, the cuticular composition of butterflies also allowed us to discriminate between individuals of different age classes (from 1 to 21 day old; perMANOVA for complete individuals or each body part: $d f=37, \mathrm{~F}$ stats $>2.4, p<0.001$ ). Moreover, the cuticular lipid composition of abdomens, legs and wings generated a gradient distribution of increasing age classes (nMDS; Figure 2). With respect to sex, the discrimination between ages remained significant when the MSP components were excluded from the analysis $(p<0.001)$. Respectively, 1,4 , 25,6 , and 29 compounds were found to be indicative of the age classes of $1,3,8,14$, and 21 day old individuals (ICA, Supplement 2). Sampling wings and legs was again sufficient to obtain almost all indicative compounds found in complete individuals (respectively, 1, 4, 21, 4, and 23 age-indicative compounds in legs and wings; Supplement 2).

\section{SUBSET OF POSSIBLY BEHAVIORALLY ACTIVE CUTICULAR COMPOUNDS}

We identified above, from the GC-MS dataset, a subset of compounds allowing the discrimination of body parts (85 compounds), sex (63 compounds), and age (89 compounds) (Supplement 2). The indicative value of a compound varied between zero and one according to the ICA and was highly correlated to the number of times that this compound significantly contributed to the discrimination of body parts, sex or age (between zero and 47 times; Supplement 2) (Figure 3). Compounds that were most indicative of body parts, sex or age,

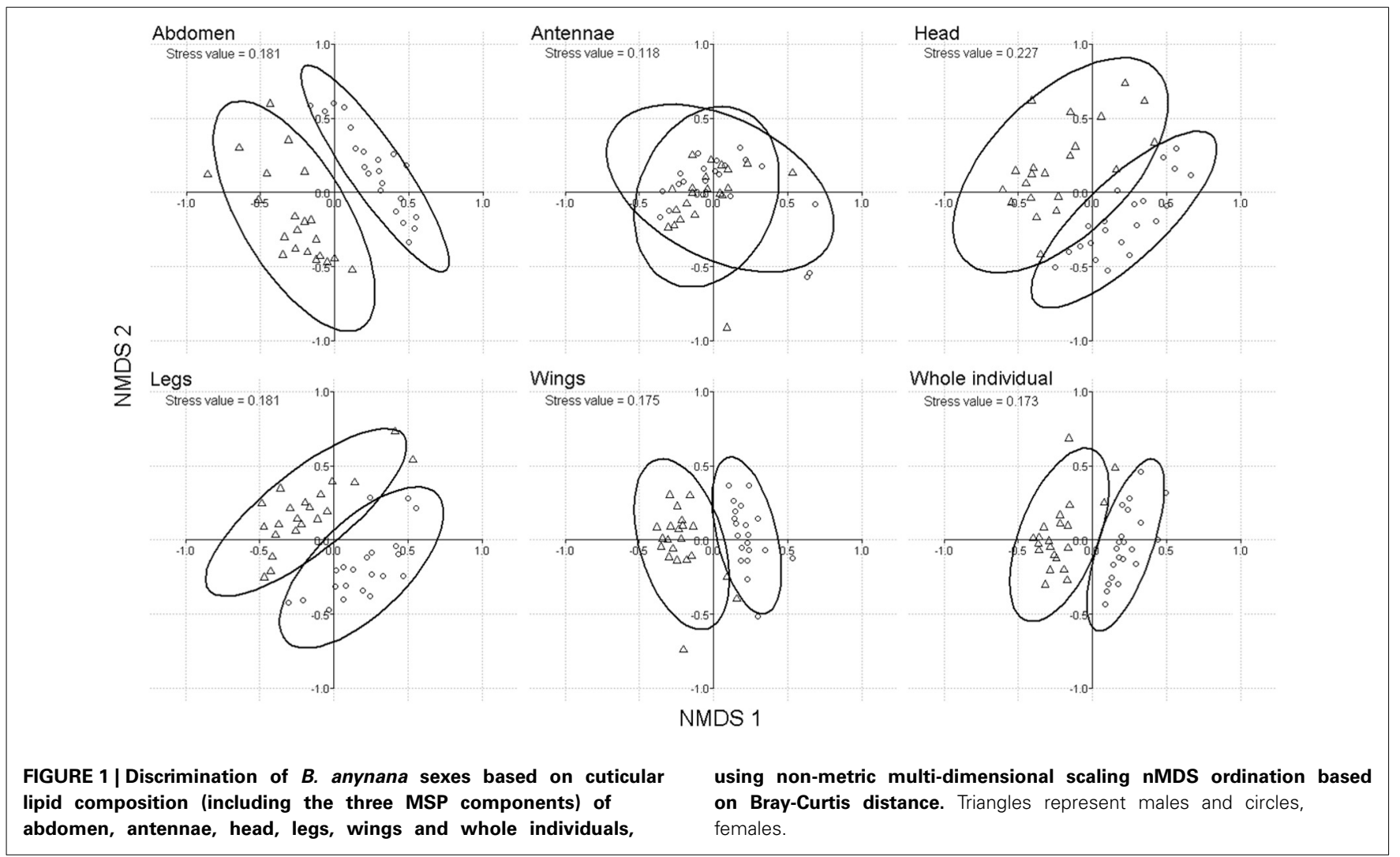



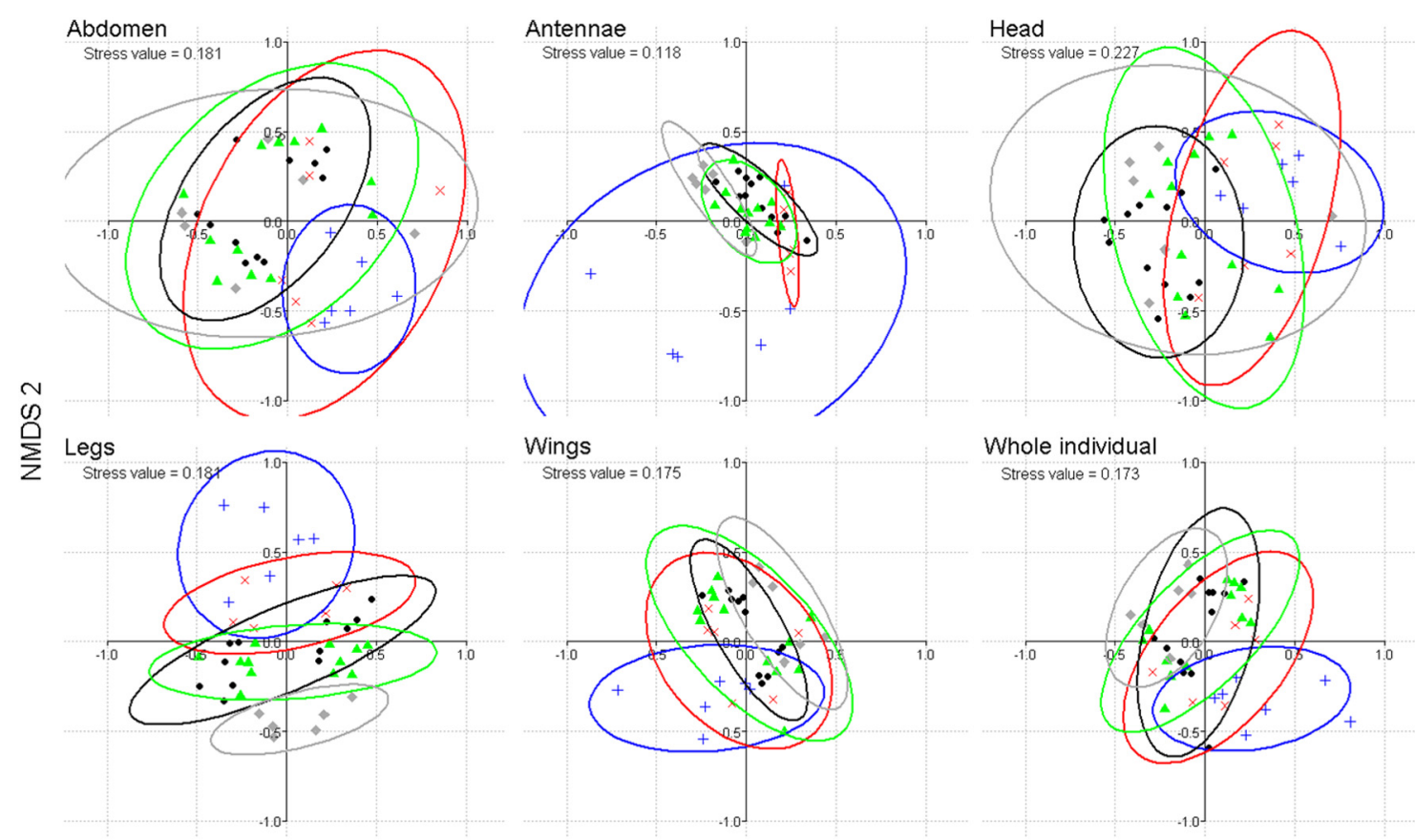

NMDS 1

FIGURE 2 | Discrimination of $B$. anynana age classes (males and females) (1-day (blue), 3-day (red), 8-day (black), 14-day (green) and 21-day (gray) old) based on cuticular lipid composition (including the three MSP components) of abdomen, antennae, head, legs, wings and whole individuals, using nMDS ordination based on Bray-Curtis distance.

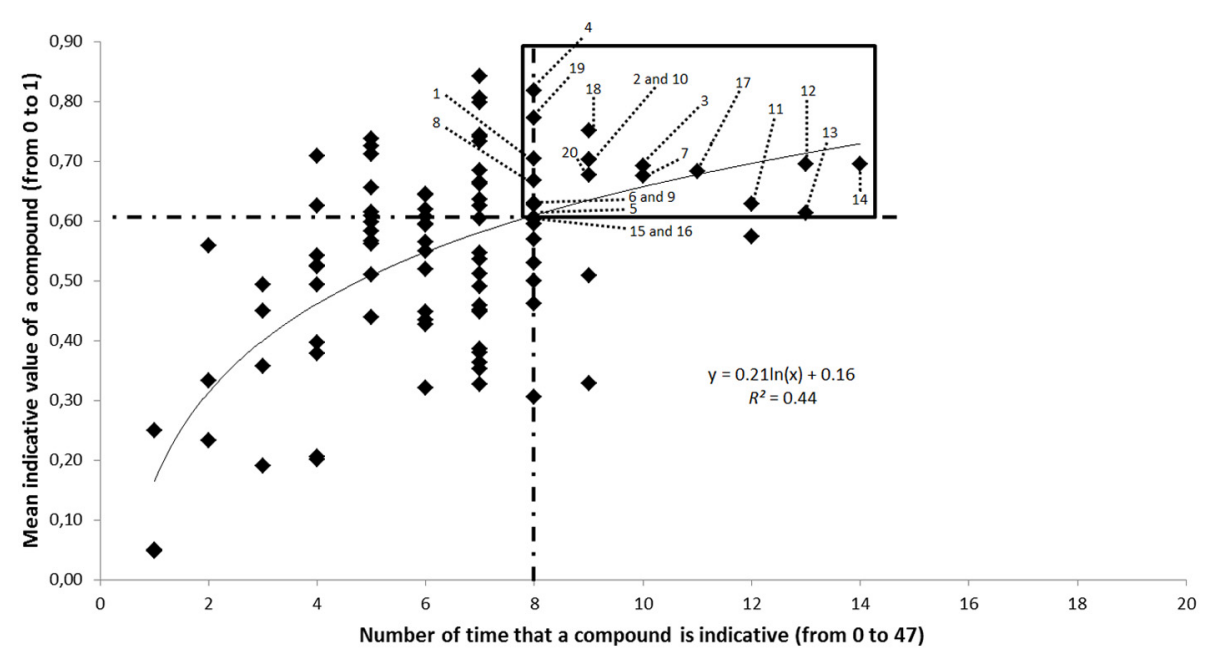

FIGURE 3 | Correlation between the indicative value of a compound ( $Y$ axis, between 0 and 1 , based on indicative compound analysis (ICA), see S2 for raw data) and the number of times that this compound is indicative and allows for the discrimination of body parts, sex and age ( $X$ axis, between 0 and 47, see $S 2$ for raw data). A logarithmic relationship was found between the two variables (coefficient of determination $R^{2}=0.44$ ). Dashed lines correspond to the values of two variables for the three MSP components that were used as a threshold for selecting the most indicative compounds, i.e., a mean indicative value $\geq 0.6$ and a number of times that a compound is indicative $\geq 8$. List of compounds from number 1 to 20 : 1 .

Z-9-tetradecenol (MSP1); 2. Heptadecane; 3. Hexadecanal (MSP2); 4. 6,10,14-trimethyl-pentadecan-2-ol (MSP 3); 5. Heptadecenal; 6Unidentified $(R t=19.20)$; 7. Octadecanal; 8. Phytol; 9. 1-eicosanol; 10. Pentacosane; 11. Hexacosane; 12. Heptacosane; 13. Octacosane; 14. Nonacosane; 15. Triacontane; 16. Triacontanal; 17. Dimethyl-tritriacontane; 18. Unidentified hydrocarbon $(R t=30.47)$; 19. Dimethyl-pentatriacontane; 20 . Hexatriacontane. 
such as the three previously identified MSP components, had an indicative value of 0.6 or higher and were discriminative for eight or more factor levels (Supplement 2). In this regard, we selected a subset of 20 highly indicative compounds which complied with the same thresholds (Table 2). These compounds were more repeatable (intra-category Spearman correlation of compounds for whole individuals: $r=0.94 \pm 0.04 ; R^{2}=0.88 \pm$ 0.07 ; mean $\pm \mathrm{SE}$ ) compared to other, less indicative compounds $\left(r=0.77 \pm 0.12 ; R^{2}=0.60 \pm 0.18\right.$; mean $\left.\pm \mathrm{SE}\right)$. The 20 highly indicative compounds were on average more abundant (1346.4 \pm $1994.6 \mathrm{ng}$; mean $\pm S D$ ) than other, less indicative, compounds $(225.9 \pm 507.2 \mathrm{ng}$; mean $\pm S D)$. Among these 20 indicative compounds, eight were indicative of male sex (six were more abundant in males than in females and two were present in males only) and four were indicative of females (all due to their higher abundance in females compared to males) (Supplement 1). Ten compounds of this subset were more abundant $(2510.3 \pm 2317.3$ ng; mean $\pm S D$ ) than the mean abundance found for all cuticular lipids $(443.4 \pm 1070.7 \mathrm{ng}$; mean $\pm S D$ ) (in italics in Table 2).

\section{VALIDATION OF THE LIST OF INDICATIVE COMPOUNDS BY GC-FID}

Based on the results obtained by GC-MS, we decided to confirm the statistical validity of the identified top 10-20 indicative compounds by sampling a larger number of individuals $(n=3-18$ per group; $n=106$ individuals in total) using the GC-FID methodology. We expected that the two GC methods (GC-MS and GCFID) used in this study should yield similar results with respect to the compounds that are indicative of sex, age, or body parts, at least when these indicative compounds are abundant on B. anynana as trace compounds were only detectable by GC-MS. Here we sampled only wings and legs of individuals which were pooled in the same extract, as most indicative compounds were found in these body parts in the GC-MS analyses. We added an internal standard, palmityl acetate, for quantifying the compounds as it was absent from the cuticular extract (as shown by the GC-MS analyses). The 57 cuticular compounds detected and identified by GC-FID (Supplement 4) were also found in the GC-MS analyses (Supplement 2). Yet, 46 additional compounds detected by GC-MS were not detected by GC-FID, among which three that were only present in antennae, head and/or abdomen [Retention time (Rt hereafter) $=21.64,23.46,25.05 \mathrm{~min}$, Supplement 1] and not in legs or wings. The additional 43 GC-MS-specific compounds were not found by GC-FID due to its lower sensitivity in comparison with the GC-MS system.

The cuticular composition of leg and wing extracts again differed significantly according to sex (perMANOVA; $d f=104$, $\mathrm{F}$ stats $=57.9, p<0.001$; nMDS). We identified 25 maleindicative compounds including the three MSP components of which 15 were also indicative of male sex in GC-MS analyses (ICA, Supplement 2). Of note, two $(R t=26.65,28.98 \mathrm{~min})$ of the 25-male indicative compounds in GC-FID analyses were in contrast indicative of female sex in GC-MS analyses. We also identified eight female-indicative compounds of which three were indicative of female sex in GC-MS though one $(R t=$ $29.78 \mathrm{~min}$ ) was indicative of male sex in GC-MS analyses (ICA, Supplement 2).
The cuticular composition of butterfly legs and wings also allowed us to discriminate between individuals of 14 vs. 21 days of age (perMANOVA: $d f=101, \mathrm{~F}$ stats $=3.2, p<0.001$ ). We identified by GC-FID one $(R t=37.16 \mathrm{~min})$ and six compounds $(R t=16.43,18.12,20.19,20.80,30.33,30.47 \mathrm{~min})$ indicative of the age classes of 14- and 21-day old individuals, respectively. Of note, the compound indicative of 14-day old individuals in GC-FID was indicative of eight-day old butterflies in GC-MS. Among the six compounds indicative of 21-day old individuals in GC-FID, three of them $(R t=18.12,30.33,30.47 \mathrm{~min})$ were indicative of the same age class in GC-MS while the three others $(R t=16.43,20.19,20.80 \mathrm{~min})$ were not indicative of age in GC-MS (ICA, Supplement 2).

In summary, using GC-MS analyses on various body parts 15 out of the 20 compounds are statistically the most indicative of sex and age and remained indicative of sex and age in GC-FID analyses performed on legs and wings only (in bold in Table 2). This included the 10 most abundant compounds among the list of 20 indicative compounds that were found both by GC-MS and GC-FID analyses.

\section{COMPARISON OF GC-FID AND GC-MS ANALYSES}

Some discrepancies were found between GC-MS and GC-FID analyses, regarding first the identity of the indicative compounds (5 out of 20 compounds indicative of sex or age in GC-MS analyses were not found to be indicative in GC-FID analyses, see above), and second the type of information provided by the presence of a specific compound (for example, the compound with Rt 29.78 min was indicative of male sex in GC-MS but of female sex in GC-FID). Variation in abundance of each compound across samples is likely responsible for the discrepancies observed between the GC-MS and GC-FID analyses. This variation may be due to the used methodology (GC-MS vs. GC-FID) or to the biological diversity inherent in B. anynana as different individuals were sampled for the GC-FID and GC-MS analyses. To distinguish between these two possibilities, we assessed the average level of correlation between pairs of samples obtained from either the same methodology (MS-MS comparison, 159 correlations; and FID-FID comparison, 437 correlations) or obtained from the two different methodologies (MS-FID comparison, 296 correlations). The average level of correlations of compounds abundance was satisfying when GC-MS and GC-FID methods were compared ( $r=0.63 \pm 0.13$; mean \pm SE; Supplement 5); Yet, the average correlation obtained when the two methods are compared is lower than the average correlation obtained between pairs of individuals sampled by the same method (FID-FID comparison: $r=0.72 \pm 0.13$; mean \pm SE; MS-MS comparison: $r=$ $0.88 \pm 0.10$; mean $\pm \mathrm{SE}$ ). Thus, the differences observed in the list of indicative compounds for sex and age are partly due to the methods of sampling, and partly due to the biological variability of the samples.

\section{COURTSHIP INVOLVES SPECIFIC GUSTATORY CONTACTS BETWEEN SEXES}

We recorded a total of 19 instances (involving 17 individuals) of dust transfer between sexes: from the male antennae to the wings of three females, from the female antennae to the wings of five 


\begin{tabular}{|c|c|c|c|c|c|c|c|c|c|c|c|c|c|c|c|}
\hline \multirow{2}{*}{ 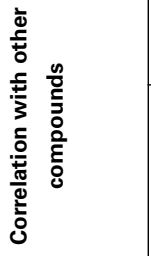 } & - & \begin{tabular}{ccc}
0 & 0 \\
\hdashline & 0 \\
0 & 0
\end{tabular} & \begin{tabular}{c|cc}
$\infty$ & $\infty$ \\
$\infty$ & $\infty$ \\
\hdashline & $\infty$ & 0 \\
0
\end{tabular} & $\stackrel{\substack{\infty \\
\infty \\
\infty \\
0}}{0}$ & $\begin{array}{l}\bar{\infty} \\
0 \\
0\end{array}$ & $\stackrel{\substack{\infty \\
\infty}}{\circ}$ & 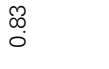 & \begin{tabular}{c|c|c}
$\infty$ & $\infty$ \\
0 & $\infty$ \\
0 & 0 & 0
\end{tabular} & $\begin{array}{c}\infty \\
\infty \\
0 \\
0\end{array}$ & & & & & \multicolumn{2}{|l|}{ 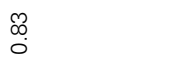 } \\
\hline & $\begin{array}{ll} \\
0\end{array}$ & & \begin{tabular}{l|l}
$\stackrel{0}{0}$ & $\infty$ \\
$\infty$ & $\infty$ \\
$\stackrel{\infty}{\infty}$ & $\stackrel{\sim}{\sim}$ \\
\end{tabular} & 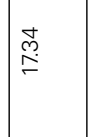 & 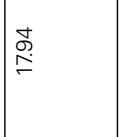 & $\begin{array}{l}\hat{\theta} \\
\dot{\varphi}\end{array}$ & $\stackrel{\circ}{\stackrel{i}{i}}$ & 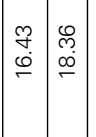 & $\begin{array}{l}\infty \\
\infty \\
\stackrel{\sim}{\infty} \\
\stackrel{n}{n}\end{array}$ & & & & & $\underset{\substack{N \\
\infty}}{\stackrel{\infty}{\infty}}$ & \\
\hline \multirow{3}{*}{ 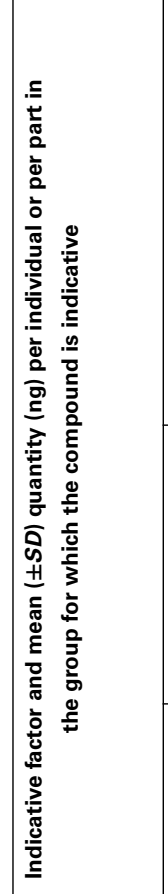 } & 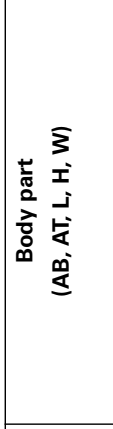 & 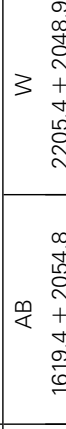 & 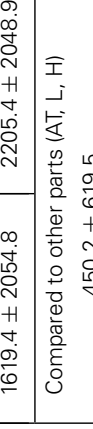 & 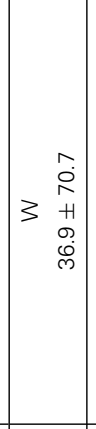 & 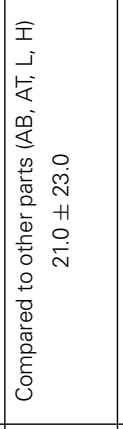 & 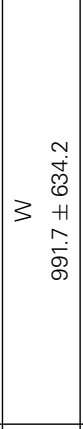 & 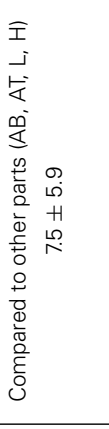 & 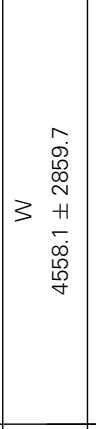 & 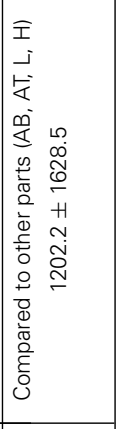 & 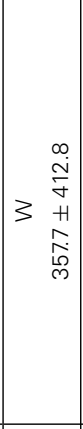 & 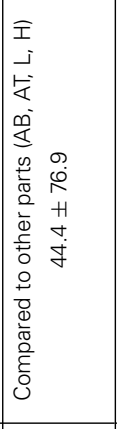 & 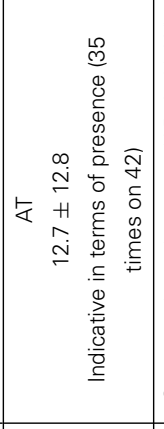 & 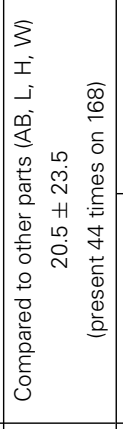 & 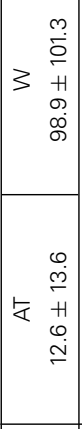 & 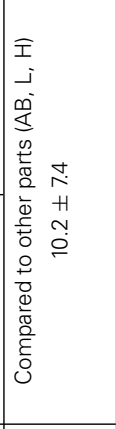 \\
\hline & 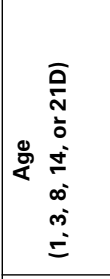 & - & & 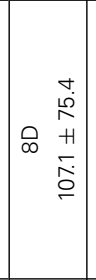 & 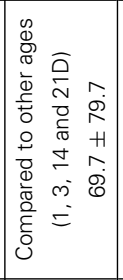 & 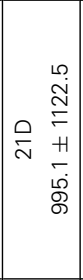 & 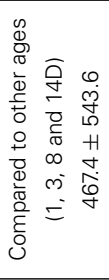 & 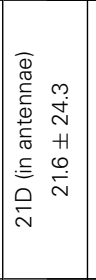 & 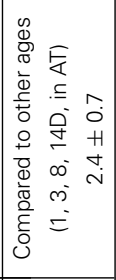 & 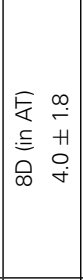 & 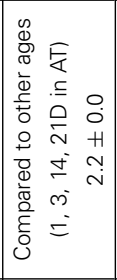 & 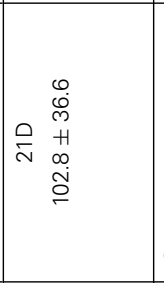 & 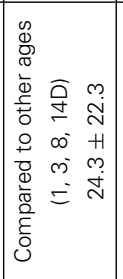 & 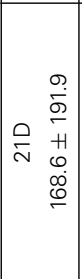 & 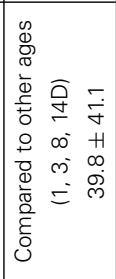 \\
\hline & 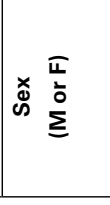 & 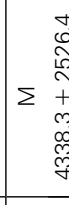 & 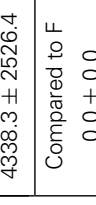 & 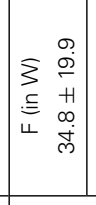 & 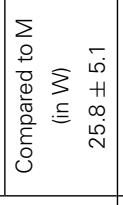 & $\begin{aligned} & 0 \\
& 0 \\
& 0 \\
& 0 \\
& \Sigma+ \\
& 0 \\
& 0 \\
& 0 \\
& 0 \\
& 0 \\
& 0\end{aligned}$ & 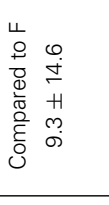 & 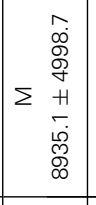 & 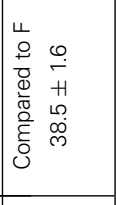 & 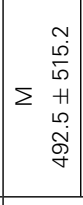 & 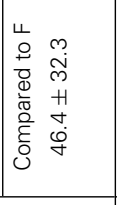 & 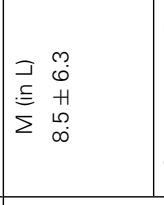 & 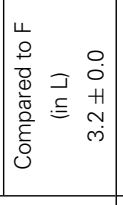 & 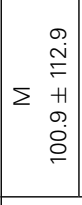 & 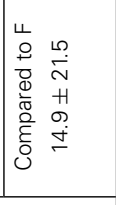 \\
\hline 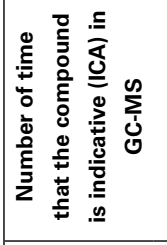 & & $\infty$ & & o & & 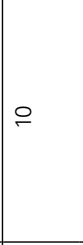 & & $\infty$ & & $\infty$ & & $\infty$ & & 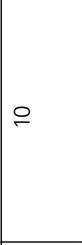 & \\
\hline 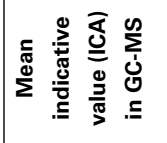 & & $\stackrel{尺}{i}$ & & $\begin{array}{l}0 \\
i \\
0\end{array}$ & & $\stackrel{8}{\circ}$ & & 齐 & & : & & مَّ & & $\begin{array}{l}0 \\
0 \\
0\end{array}$ & \\
\hline 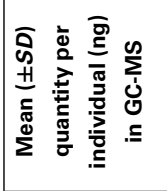 & & 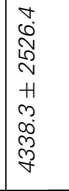 & & 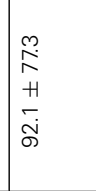 & & $\begin{array}{l}10 \\
\infty \\
\infty \\
0 \\
+1 \\
0 \\
0 \\
0 \\
0 \\
0\end{array}$ & & $\begin{array}{l}m \\
0 \\
0 \\
0 \\
0 \\
0 \\
+1 \\
0 \\
0 \\
1 \\
1 \\
10\end{array}$ & & $\begin{array}{l}\infty \\
o j \\
o j \\
o \\
+ \\
+1 \\
\infty \\
\infty \\
\tilde{m} \\
\tilde{m}\end{array}$ & & \begin{tabular}{l}
$L$ \\
$\infty$ \\
$\infty$ \\
$m$ \\
$H$ \\
\multirow{N}{N}{} \\
$m$
\end{tabular} & & $\begin{array}{l}0 \\
\ddot{N} \\
o \\
+1 \\
\tilde{N} \\
0 \\
0\end{array}$ & \\
\hline 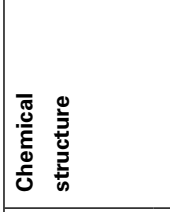 & & 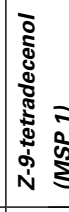 & & 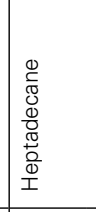 & & 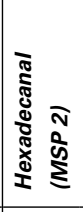 & & 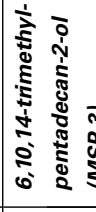 & & 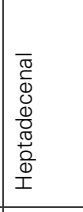 & & 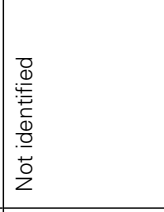 & & 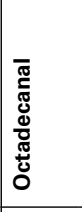 & \\
\hline 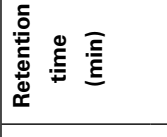 & & $\begin{array}{l}8 \\
6 \\
0\end{array}$ & & \begin{tabular}{|l|}
$\infty$ \\
$\infty$ \\
0 \\
$\varrho$
\end{tabular} & & $\stackrel{N}{\infty}$ & & $\begin{array}{l}\stackrel{0}{0} \\
\infty \\
\infty\end{array}$ & & \begin{tabular}{|l|} 
\\
$\dot{0}$ \\
$\dot{\sigma}$
\end{tabular} & & 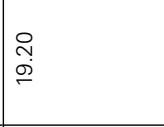 & & $\frac{9}{\mathrm{~N}}$ & \\
\hline í & & - & & $\sim$ & & $m$ & & † & & \llcorner & & 0 & & r & \\
\hline
\end{tabular}




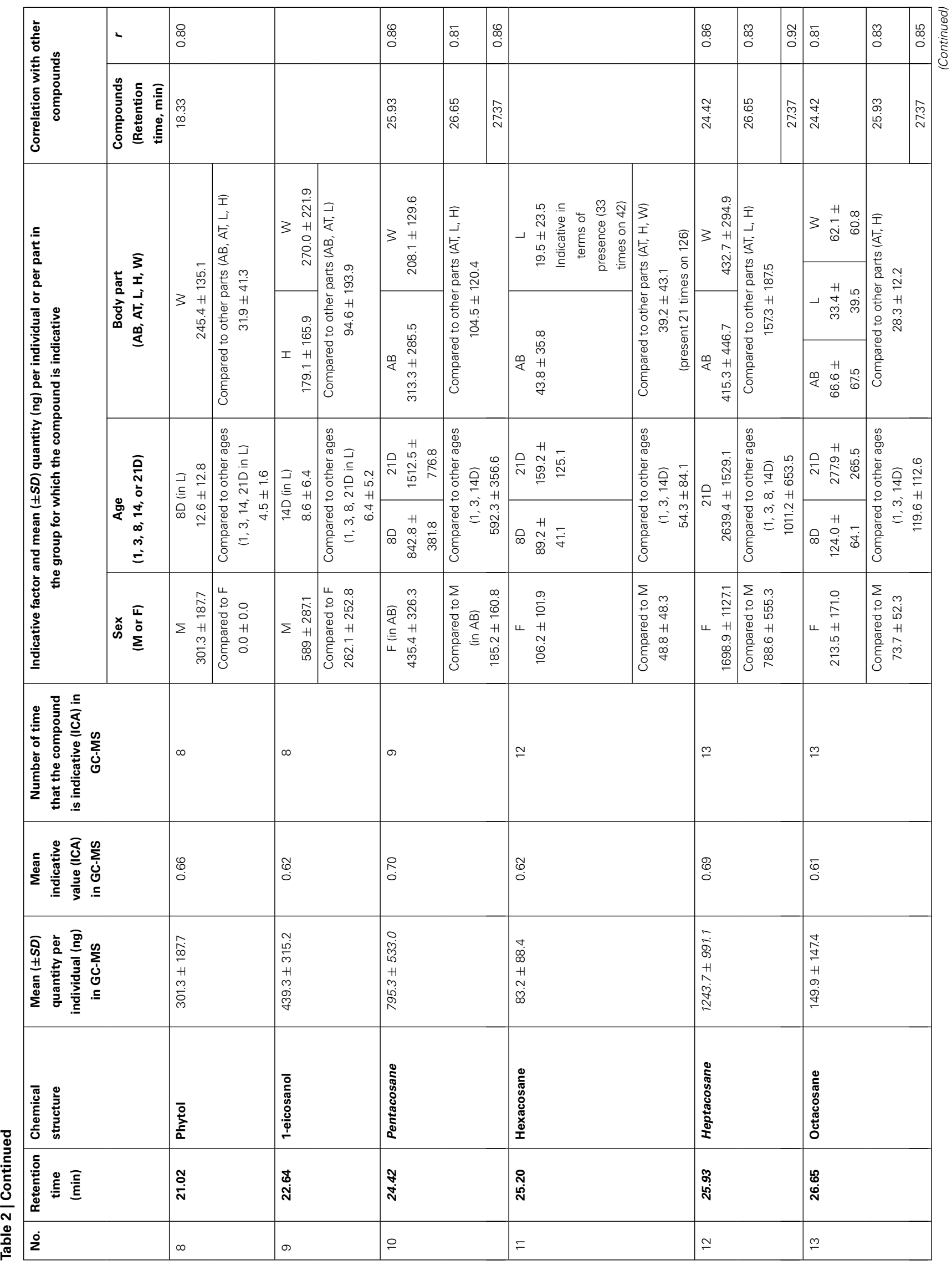




\begin{tabular}{|c|c|c|c|c|c|c|c|c|c|c|c|c|c|}
\hline \multirow{2}{*}{ 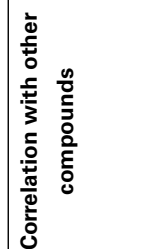 } & - & \begin{tabular}{|l}
$\infty$ \\
$\infty$ \\
0 \\
0
\end{tabular} & హ. & & & & & & & \multicolumn{2}{|l|}{$\mid \begin{array}{c}\bar{\infty} \\
0 \\
0\end{array}$} & \multicolumn{2}{|l|}{$\mid \begin{array}{l}\bar{\infty} \\
0 \\
0\end{array}$} \\
\hline & 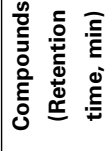 & $\underset{\stackrel{N}{*}}{\stackrel{\text { V}}{\sim}}$ & 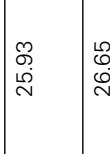 & & & & & & & \multicolumn{2}{|l|}{ 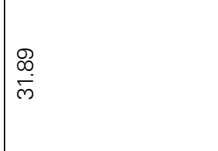 } & \multicolumn{2}{|l|}{$\begin{array}{l}\text { ff } \\
\text { di }\end{array}$} \\
\hline \multirow{3}{*}{ 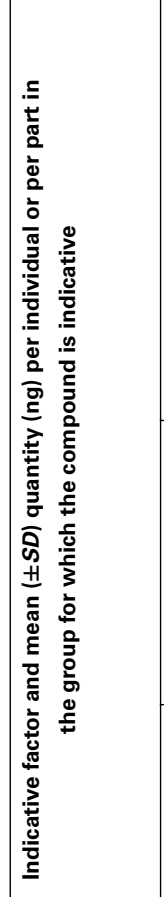 } & 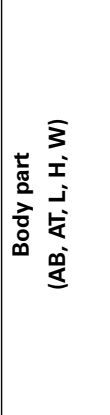 & 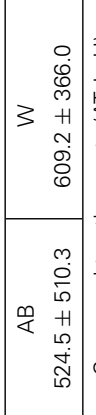 & 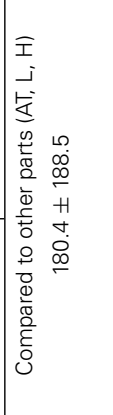 & $3 \underset{\substack{\stackrel{N}{+} \\
\stackrel{\infty}{+}}}{\stackrel{\infty}{\rho}}$ & 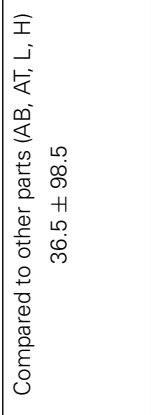 & 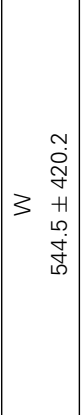 & 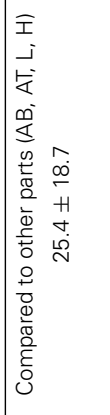 & $\mid \begin{array}{ll} & \\
& \\
0 \\
0 \\
0 \\
0 \\
3 \\
1 \\
0 \\
0 \\
0 \\
0 \\
0\end{array}$ & 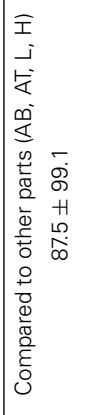 & 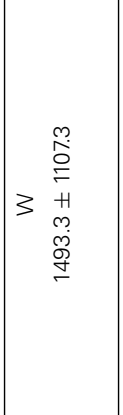 & 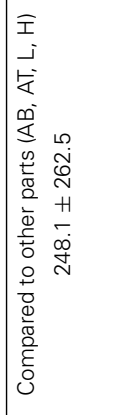 & 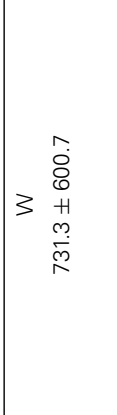 & 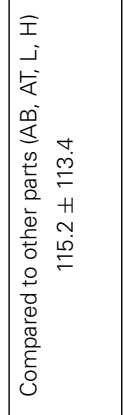 \\
\hline & 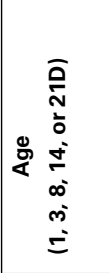 & 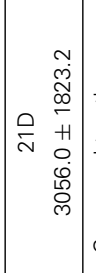 & 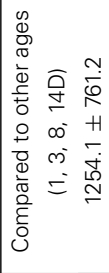 & 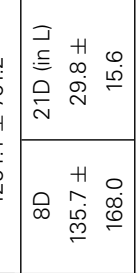 & 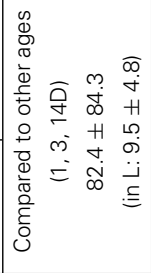 & 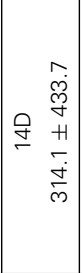 & 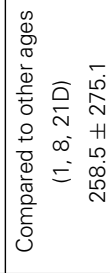 & 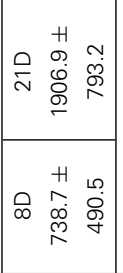 & 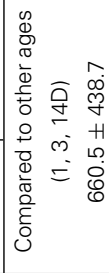 & 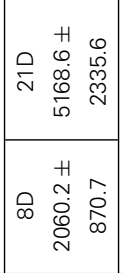 & 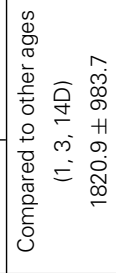 & 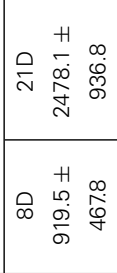 & 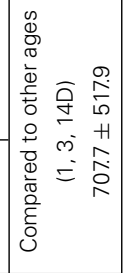 \\
\hline & ڤ & 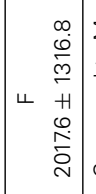 & 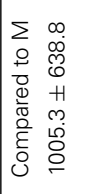 & 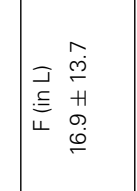 & 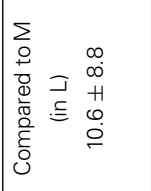 & 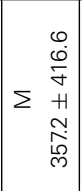 & 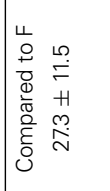 & 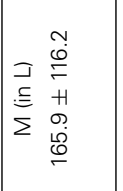 & 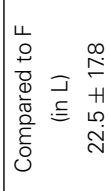 & 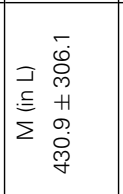 & 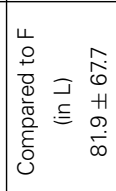 & 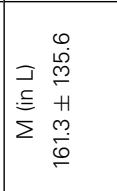 & 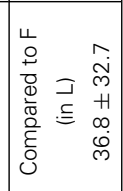 \\
\hline 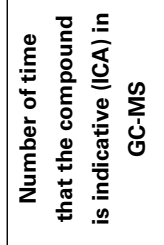 & & $\stackrel{\Xi}{ }$ & & $\infty$ & & $\infty$ & & $=$ & & 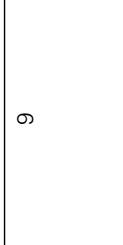 & & $\infty$ & \\
\hline 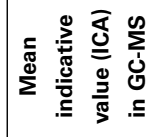 & & $\begin{array}{l}8 \\
0 \\
0\end{array}$ & & 总 & & $\stackrel{\circ}{\circ}$ & & \begin{tabular}{l}
$\infty$ \\
\hdashline \\
\hdashline
\end{tabular} & & $\mid \begin{array}{l}\stackrel{2}{2} \\
0 \\
0\end{array}$ & & 会 & \\
\hline 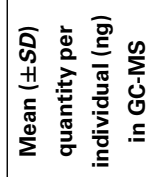 & & 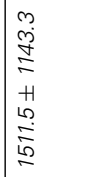 & & 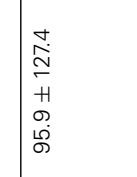 & & 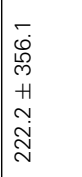 & & $\begin{array}{l}1 \\
\mathbb{8} \\
0 \\
+1 \\
0 \\
0 \\
\infty \\
\infty\end{array}$ & & 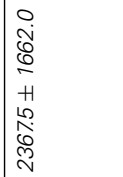 & & 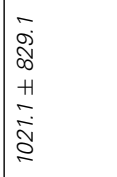 & \\
\hline 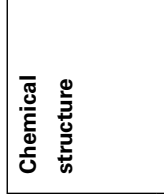 & & 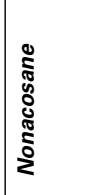 & & 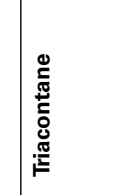 & & 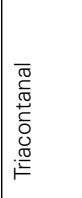 & & 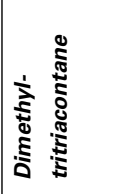 & & 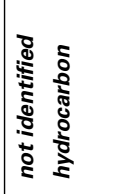 & & 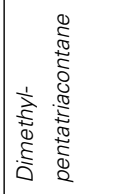 & \\
\hline 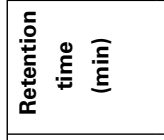 & & 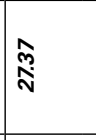 & & $\begin{array}{l}\stackrel{0}{\infty} \\
\stackrel{\infty}{\infty}\end{array}$ & & 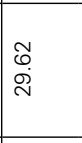 & & 耪 & & 官 & & $\mid \begin{array}{l}\infty \\
\stackrel{\infty}{m}\end{array}$ & \\
\hline ì & & 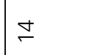 & & $\stackrel{2}{\llcorner}$ & & $\mathscr{0}$ & & $\neq$ & & $\stackrel{\infty}{\sim}$ & & $\stackrel{\rho}{\circ}$ & \\
\hline
\end{tabular}




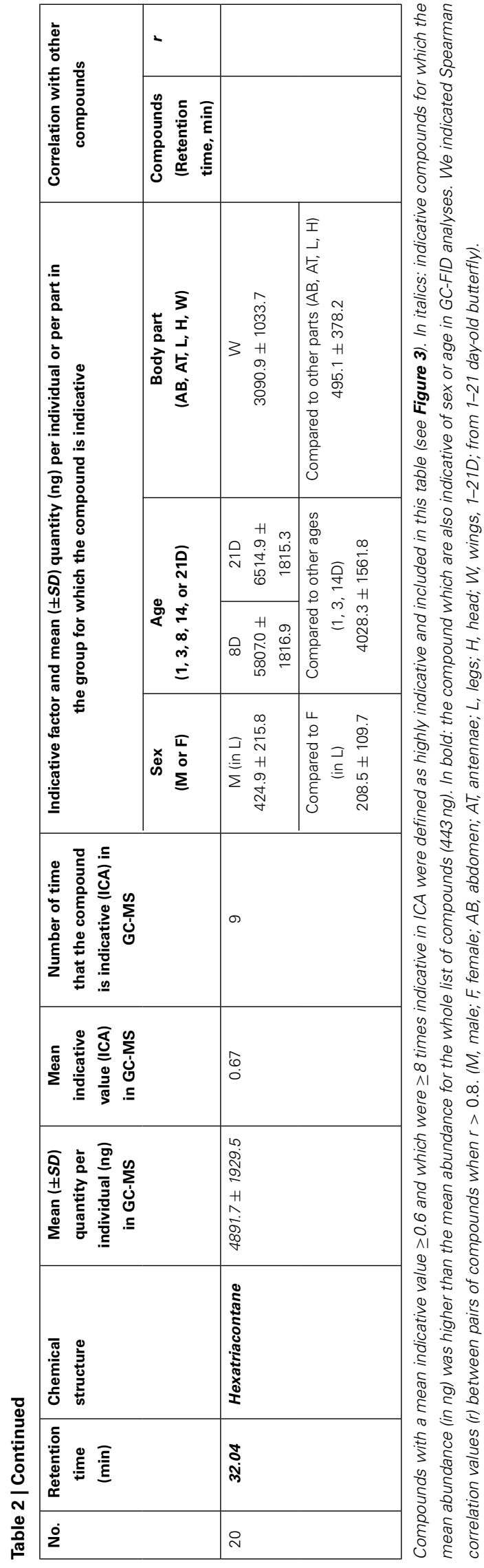

males, from the female legs to the head of six males (including male antennae in one instance and male proboscis in another one) and to the wings of one male, and from the male legs to the abdomen of one female and to the head of another female. These dust transfers occurred during courtship as (i) males and females come close to each other only during such sexual interactions (Nieberding et al., personal observation; Holveck et al., in preparation), and (ii) each sex was dusted with a different color, excluding within-individual transfer of dust of different colors due to grooming. Although the number of contacts between individuals remained limited, these results show that both sexes have the opportunity to taste each other by contact of their antennae and legs to different and specific body parts (head, wings, abdomen) during courtship. These contacts were not random as the body parts mostly touched by the other sex during courtship were the ones with the highest between-sex difference in cuticular composition, namely all body parts but the antennae (18 contacts with wings, head, abdomen, proboscis and legs against 1 with antennae, $\mathrm{Chi}^{2}=15.2, P<0.001$; see Figure 1 for differences in cuticular composition between body parts). Yet, the antennae represent a small target compared to the rest of the body which may partly explain that the other body parts entered more often into contact.

\section{DISCUSSION}

Despite accumulating evidence in both social and non-social insects (Carlson et al., 1971; Chase et al., 1992; Tregenza and Wedell, 1997; Bonduriansky, 2001; Rantala et al., 2002, 2003; Rantala and Kortet, 2004; Kortet and Hedrick, 2005; Nieberding et al., 2008; Thomas and Simmons, 2009), the role of cuticular lipids with low or no volatility in transferring information between individuals remains surprisingly poorly investigated in Lepidoptera, a model group for the study of olfactory communication using volatile sex pheromones in mate choice and sexual selection (Johansson and Jones, 2007). Here, we found in the butterfly $B$. anynana over a hundred cuticular compounds composed by up to 40 carbon atoms by GC-MS. The number of cuticular compounds found in B. anynana is much higher compared to what is found in Drosophila or in Orthoptera [usually below 20 compounds (Howard and Blomquist, 2005; Yew et al., 2009; Everaerts et al., 2010; Ferveur and Cobb, 2010)]. The restricted number of compounds in Drosophila compared to what is found in B. anynana and in another butterfly studied to date (150 compounds found in Idea leucone; Schulz and Nishida, 1996) suggests that the fly model may not be representative of the diversity of organisms using cuticular lipids for mate choice. As such, there is a need for chemical and functional characterizations of the chemical profiles of additional, phylogenetically distant, species. Moreover, the high number of cuticular compounds found in B. anynana suggests that refined information about mate quality may be transferred using cuticular lipids during close-range courtship, in agreement with our behavioral observations that males and females taste specific body parts of potential mating partners during courtship.

The large number of cuticular compounds has often precluded the identification of their chemical structure, while their lipophilic nature and length have usually hampered 
the identification of the behaviorally active compounds by electro-antennogram recordings or by the manipulation of the chemical profile of alive individuals (Hefetz et al., 2010). In Lepidoptera, most pheromones identified to date are classified as "type I" and "type II" compounds. "Type I" pheromones consist in primary alcohols and their derivatives (acetates and aldehydes) with a straight chain from 10 to 18 carbon atoms while "type II" pheromones comprise polyunsaturated hydrocarbons and their epoxy derivatives with a straight chain from 17 to 23 carbon atoms (Millar, 2000; Ando, 2004; Millar et al., 2010). In the butterfly B. anynana, most cuticular lipids do not belong to the "type I" or "type II" compounds typically found in the sex pheromone gland of moths (Jurenka, 2004) but rather we found mostly n-alkanes, methyl-branched alkanes and functional groups (alcohol, aldehyde, ketone or acid) as described in another butterfly, Pieris rapae (Supplement 6; Arsene et al., 2002). Most B. anynana indicative compounds were previously shown to be behaviorally active as male or female sex pheromone components in other insects including moths and butterflies such as Colias eurytheme (Supplement 6). Chemical structures similar to those found in B. anynana were also found in other insects (www.pherobase. com), where they can play a role in cuticle waterproofing but may also have a specific function in insect chemical communication (sex pheromone, kairomones, species recognition, fertility cues,... ) (Blomquist and Bagnères, 2010). These cuticular compounds were extracted with a non-polar solvent (n-hexane) and we expect the chemical cuticular diversity to be even larger if additional solvents with a large range of polarities were used. There may also be additional cuticular compounds of molecular weight higher than 40 carbons in B. anynana, which could be screened in future analyses using matrix-assisted laser desorption/ionization time-of-flight MS (MALDI-TOF-MS) (Cvačka et al., 2006). In addition, UV-LDI-o-TOF-MS was used for the identification of oxygenated polyenes in D. melanogaster, whose polar compounds are hardly detected by classic GC-MS analyses (Yew et al., 2009). However, the UV-LDI-o-TOF-MS technique is rather insensitive to monoenes and does not allow detection of alkanes, the major class of compounds found in our B. anynana cuticular extracts (Table 1).

B. anynana cuticular lipids were on average much more abundant $(443 \pm 1070 \mathrm{ng}$ per compound per individual; $46 \pm 1 \mu \mathrm{g}$ of total compound per individual of which $27 \pm 2 \mu \mathrm{g}$ consisted of the 20 highly indicative compounds; see Supplement 2) than in other Lepidoptera (www.pherobase.com). In addition, most B. anynana indicative compounds varied quantitatively in abundance, rather than qualitatively, across categories (Supplement 1): males had a larger number of sex-specific compounds than females and the indicative compounds were more abundant in males than in females (see Results). This is similar in D. melanogaster for which the abundance of C23-C25 compounds, including 7-tricosene (7T) and 7-pentacosene (7P), is higher in males whereas females display a higher proportion of C25-C27 compounds including 7,11-heptacosadiene (7,11-HD) and 7,11-nonacosadiene (7,11-ND) (Jallon, 1984; Hefetz et al., 2010). Cases of both marked, and absence of, sexual dimorphism in cuticular hydrocarbons were found in several other species of the "melanogaster" subgroup (Cobb and Jallon, 1990). A similar sexual differentiation in the composition of cuticular lipids was also found in some Lepidoptera [e.g., Papilio polytes (Ômura and Honda, 2005), Lasiommata species (Dapporto, 2007)], but not in others [e.g., Pieris rapae (Arsene et al., 2002)]. Such variation in the level of sexual dimorphism across closely related taxa suggests that sexual selection may be a strong driving force in the evolution of the composition in cuticular lipids.

Furthermore, quantitative variation of cuticular lipid composition was indicative of age classes. In this regard, we previously showed that variation in the abundance of three volatile malespecific sex pheromone components allowed females to detect male age and inbreeding status and to mate preferentially with middle-aged and outbred males (Nieberding et al., 2012; Van Bergen et al., 2013). We here showed that male and female age differences also induced significant changes in cuticular lipid composition across all body parts. The indicative value of the three MSPs $(0.32 \pm 0.32$; mean $\pm S D)$ for age was lower than the one of the 17 other highly indicative compounds $(0.66 \pm 0.10$; mean $\pm S D$ ) suggesting that some cuticular lipids may be more indicative of age. Therefore, we suggest that, rather than simply providing back-up message (reviewed in Candolin, 2003) on male age during sexual interactions at a closer range, some cuticular compounds may provide additional, potentially fine-scale, information to complement the information already provided by the MSP composition about male age during sexual interactions at a closer range (Robertson and Monteiro, 2005).

Natural variation in cuticular lipid composition across body parts, sex and age classes, high abundance of the most indicative compounds, strong sexual dimorphism both in terms of abundance and number of indicative cuticular lipids, and non-random gustatory contacts during courtship together suggest that cuticular lipids may provide a substrate for adaptive evolution through mate choice and sexual selection. The large diversity of cuticular lipids on B. anynana body suggests more complex gustatory interactions than hitherto appreciated in non-social insects.

\section{AUTHOR CONTRIBUTIONS}

Designed research: Stéphanie Heuskin, Caroline M. Nieberding, Georges Lognay. Performed research: Stéphanie Heuskin, Christophe Pels, Marie-Jeanne Holveck. Contributed analytical tools: Stéphanie Heuskin, Tobias Engl, Martin Kaltenpoth, Georges Lognay. Analyzed data: Stéphanie Heuskin, Maryse Vanderplanck, Cédric Taverne, Paul Bacquet, Caroline M. Nieberding, Georges Lognay. Statistical analyses: Stéphanie Heuskin, Maryse Vanderplanck, Cédric Taverne, Caroline M. Nieberding, Paul Bacquet. Wrote the paper: Stéphanie Heuskin, Caroline M. Nieberding, Georges Lognay, Maryse Vanderplanck, Cédric Taverne. Revised the paper: Stéphanie Heuskin, Caroline M. Nieberding, Georges Lognay, Maryse Vanderplanck, Cédric Taverne, Christophe Pels, Tobias Engl, Martin Kaltenpoth, Marie-Jeanne Holveck, Paul Bacquet

\section{ACKNOWLEDGMENTS}

We are grateful to A. Guillet (SMCS at UCL, Belgium) for his help in statistical analyses, to L. Fléchon for collecting the behavioral data under Dr. Marie-Jeanne Holveck's supervision, and to Dr. Ian Dublon (Group of Evolutionary Ecology and Genetics, 
UCL, Belgium), native English speaker, for editing the paper. This research was supported by the Belgian "Fonds national pour la recherche scientifique" (FNRS) (FRFC grant $\mathrm{n}^{\circ} 2.4560 .11$ ) and by the Université catholique de Louvain (ARC grant $\mathrm{n}^{\circ} 10 / 15-$ 031 and FSR grant $n^{\circ} 372605031$ to Caroline M. Nieberding). Maryse Vanderplanck is a CR funded by the Belgian FNRS. This is publication BRC 276 of the Biodiversity Research Center.

\section{SUPPLEMENTARY MATERIAL}

The Supplementary Material for this article can be found online at: http://www.frontiersin.org/journal/10.3389/fevo.2014.00037/ abstract

Supplement 1 | (Dataset, Excel file). List of $B$. anynana cuticular extracts used for the GC-MS analyses. The retention time ( $\mathrm{min}$ ) and abundance (ng) of each 103 compounds are indicated for each 210 samples.

Supplement 2 | (Dataset, Excel file). List of the cuticular compounds found in, and results of the Indicative Compound Analysis (ICA) performed for, the GC-MS (left) and GC-FID (right) B. anynana cuticular extracts. From left to right, we listed for each of the 103 compounds their retention time, retention index, tentative name, criteria used for attributing the tentative chemical structure, abundance (ng), repeatability across samples and correlated abundance with other compounds (reported for Spearman correlations $r>0.8$ ). Next we provided the indicative value (between 0 and 1) of each compound obtained from the ICA for discriminating among body parts, sex or age, based on GC-MS (left) or GC-FID samples (right). Of note, the retention times of the three, previously identified, MSP components were MSP1 $=16.43 \mathrm{~min}, \mathrm{MSP} 2=18.12 \mathrm{~min}$, and $\mathrm{MSP} 3=$ $18.46 \mathrm{~min}$ (Nieberding et al., 2008). The 20 most indicative compounds are highlighted in bold (see also Table 2).

Supplement 3 | (Figure 4 Tiff file). Representative GC-MS chromatograms (from 15 to $40 \mathrm{~min}$ ) of wing extracts of a 8 day-old female (A) and a 8 day-old male (B).

Supplement 4 | (Dataset, Excel file). List of B. anynana cuticular compounds found by GC-FID analyses. The retention time (min) and abundance (ng) of each 57 compounds were indicated for each of the 106 samples.

Supplement $\mathbf{5}$ | (Figure 5, Tiff File). Distribution of the spearman rank correlations for the ranked amounts of chemical compounds obtained for pairs of individuals and quantified by: (A) GC-MS vs. GC-FID $[n=57$ compounds, $N=296$ correlations, $r=0.63 \pm 0.13$ (mean \pm SE)]; (B) GC-FID ( $n=57$ compounds, for $N=437$ correlations, $r=0.72 \pm 0.13$ (mean \pm SE)]; (C) GC-MS ( $n=57$ compounds, for $N=159$ correlations, $r=0.88 \pm 0.10($ mean $\pm \mathrm{SE})]$.

Supplement 6 | (Table, Word File). Non-exhaustive list of the pheromonal function of the indicative compounds in other Lepidoptera species (based on Pherobase search on March 21st, 2014).

\section{REFERENCES}

Amrein, H., and Thorne, N. (2005). Gustatory perception and behavior in Drosophila melanogaster. Curr. Biol. 15, R673-R684. doi: 10.1016/j.cub.2005. 08.021

Anderson, M. J. (2001). Permutation tests for univariate or multivariate analysis of variance and regression. Can. J. Fish. Aquat. Sci. 58, 626-639. doi: 10.1139/ f01-004

Anderson, M. J. (2005). PERMANOVA: A FORTRAN Computer Program for Permutational Multivariate Analysis of Variance. Auckland: Department of Statistics, University of Auckland.
Andersson, J., Borg-Karlson, A.-K., Vongvanich, N., and Wiklund, C. (2007). Male sex pheromone release and female mate choice in a butterfly. J. Exp. Biol. 210, 964-970. doi: 10.1242/jeb.02726

Andersson, M. (1994). Sexual Selection. Princeton: Princeton University Press.

Ando, T. (2004). Lepidopteran sex pheromones. Top. Curr. Chem. 239, 51-96. doi: $10.1007 / \mathrm{b} 95449$

Arsene, C., Schulz, S., and Van Loon, J. J. A. (2002). Chemical polymorphism of the cuticular lipids of the cabbage white Pieris rapae. J. Chem. Ecol. 28, 2627-2631. doi: 10.1023/A:1021474820601

Baker, T. C., Nishida, R., and Roelofs, W. L. (1981). Close-range attraction of female oriental moths to herbal scent of male hairpencils. Science 214, 1359-1361. doi: 10.1126/science.214.4527.1359

Birch, M. C., Poppy, G. M., and Baker, T. C. (1990). Scents and eversible scent structures of male moths. Annu. Rev. Entomol. 35, 25-58.

Blomquist, G. J., and Bagnères, A.-G. (2010). "Introduction: history and overview of insect hydrocarbons," in Insect Hydrocarbons. Biology, Biochemistry, and Chemical Ecology, eds G. J. Blomquist and A.-G. Bagnères (Cambridge: Cambridge University Press), 3-18.

Bonduriansky, R. (2001). The evolution of male mate choice in insects: a synthesis of ideas and evidence. Bio. Rev. Camb. Philos. Soc. 76, 305-339. doi: $10.1017 /$ S1464793101005693

Böröczky, K., Park, K. C., Minard, R. D., Jones, T. H., Baker, T. C., and Tumlinson, J. H. (2008). Differences in cuticular lipid composition of the antennae of Helicoverpa zea, Heliothis virescens, and Manduca sexta. J. Insect Phys. 54, 1385-1391. doi: 10.1016/j.jinsphys.2008.07.010

Brakefield, P. M., Beldade, P., and Zwaan, B. J. (2009). “The African butterfly Bicyclus anynana: a model for evolutionary genetics and evolutionary developmental biology," in Emerging Model Organisms: A Laboratory Manual, eds R. R. Behringer, A. D. Johnson, and R. E. Krumlauf (New York, NY: Cold Spring Harbor), 291-329.

Brakefield, P. M., and Reitsma, N. (1991). Phenotypic plasticity, seasonal climate and the population biology of Bicyclus butterflies (Satyridae) in Malawi. Ecol. Entomol. 16, 291-303. doi: 10.1111/j.1365-2311.1991.tb00220.x

Brennan, P. A., and Zufall, F. (2006). Pheromonal communication in vertebrates. Nature 444, 308-315. doi: 10.1038/nature05404

Butler. (1879). Bicyclus anynana. Ann. Mag. Nat. Hist. 3, 186-192.

Candolin, U. (2003). The use of multiple cues in mate choice. Biol. Rev. 78, 575-595. doi: $10.1017 /$ S1464793103006158

Carlson, D. A., Mayer, M. S., Silhacek, D. L., James, J. D., Beroza, M., and Bierl, B. A. (1971). Sex attractant pheromone of the house fly: isolation, identification and synthesis. Science 174, 76-78. doi: 10.1126/science.174. 4004.76

Carlson, D. A., and Milstrey, S. K. (1991). Alkanes of 4 related moth species, Helicoverpa and Heliothis. Arch. Insect Biochem. Physiol. 16, 165-175. doi: 10.1002/arch.940160303

Chase, J., Touhara, K., Prestwich, G. D., Schal, C., and Blomquist, G. J. (1992). Biosynthesis and endocrine control of the production of the German cockroach sex pheromone 3,11-dimethylnonacosan-2-one. Proc. Natl. Acad. Sci. U.S.A. 89, 6050-6054. doi: 10.1073/pnas.89.13.6050

Cobb, M., and Jallon, J.-M. (1990). Pheromones, mate recognition and courtship stimulation in the Drosophila melanogaster species sub-group. Anim. Behav. 39, 1058-1067. doi: 10.1016/S0003-3472(05)80778-X

Condamin, M. (1973). Monographie du genre Bicyclus (Lepidoptera: Satyridae). Dakar: Institut Fondamental d'Afrique Noire.

Costanzo, K., and Monteiro, A. (2007). The use of chemical and visual cues in female choice in the butterfly Bicyclus anynana. Proc. R. Soc. B Biol. Sci. 274, 845-851. doi: 10.1098/rspb.2006.3729

Cvačka, J., Jiroš, P., Šobotník, J., Hanus, R., and Svatoš, A. (2006). Analysis of insect cuticular hydrocarbons using matrix-assisted laser desorption/ionization mass spectrometry. J. Chem. Ecol. 32, 409-434. doi: 10.1007/s10886-0059008-5

Dapporto, L. (2007). Cuticular lipid diversification in Lasiommata megera and Lasiommata paramegaera: the influence of species, sex, and population (Lepidoptera: Nymphalidae). Biol. J. Linn. Soc. 91, 703-710. doi: 10.1111/j.10958312.2007.00833.x

Davie, L. C., Jones, T. M., and Elgar, M. A. (2010). The role of chemical communication in sexual selection: hair-pencil displays in the diamondback moth, Plutella xylostella. Anim. Behav. 79, 391-399. doi: 10.1016/j.anbehav.2009. 11.015 
Dussourd, D. E., Harvis, C. A., Meinwald, J., and Eisner, T. (1991). Pheromonal advertisement of a nuptial gift by a male moth (Uthetiesa ornatrix). Proc. Natl. Acad. Sci. U.S.A. 88, 9224-9227.

Ebbs, M. L., and Amrein, H. (2007). Taste and pheromone perception in the fruit fly Drosophila melanogaster. Pflugers Arch. 454, 735-747. doi: 10.1007/s00424007-0246-y

Everaerts, C., Farine, J.-P., Cobb, M., and Ferveur, J.-F. (2010). Drosophila cuticular hydrocarbons revisited: mating status alters cuticular profiles. PLoS ONE 5:e9607. doi: 10.1371/journal.pone.0009607

Ferveur, J. F., and Cobb, M. (2010). "Behavioral and evolutionary roles of cuticular hydrocarbons in Diptera," in Insect Hydrocarbons: Biology, Biochemistry and Chemical Ecology, eds G. J. Blomquist and A.-G. Bagnères (Cambridge: Cambridge University Press), 325-343. doi: 10.1017/CBO9780511711909.016

Ginzel, M. D. (2010). "Hydrocarbons as contact pheromones of longhorned beetles (Coleoptera: Cerambycidae)," in Insect Hydrocarbons: Biology, Biochemistry and Chemical Ecology, eds G. J. Blomquist and A.-G. Bagnères (Cambridge: Cambridge University Press), 375-389. doi: 10.1017/CBO9780511711909.018

Grant, G. G., Frech, D., MacDonald, L., Slessor, K. N., and King, G. G. S. (1987). Copulation releaser pheromone in body scales of female whitemarked tussock moth, Orgyia leucostigma (Lepidoptera: Lymantriidae): identification and behavioral role. J. Chem. Ecol. 13, 345-356. doi: 10.1007/BF01025894

Greenspan, R. J., and Ferveur, J.-F. (2000). Courtship in Drosophila. Annu. Rev. Genet. 34, 205-232. doi: 10.1146/annurev.genet.34.1.205

Grula, J. W., McChesney, J. D., and Taylor, O. R. (1980). Aphrodisiac pheromones of the sulfur butterflies Colias eurytheme and C. philodice (Lepidoptera, Pieridae). J. Chem. Ecol. 6, 241-256. doi: 10.1007/BF00987543

Guerrieri, F. J., Nehring, V., Jorgensen, C. G., Nielsen, J., Galizia, C. G., and D'Ettorre, P. (2009). Ants recognize foes and not friends. Proc. R. Soc. Lond. B Biol. Sci. 276, 2461-2468. doi: 10.1098/rspb.2008.1860

Hall, J. C. (1994). The mating of a fly. Science 264, 1702-1714. doi: 10.1126/science. 8209251

Hay-Roe, M. M., Lamas, G., and Nation, J. L. (2007). Pre- and postzygotic isolation and Haldane rule effects in reciprocal crosses of Danaus erippus and Danaus plexippus (Lepidoptera: Danainae), supported by differenciation of cuticular hydrocarbons, establish their status as separate species. Biol. J. Linn. Soc. 91, 445-453. doi: 10.1111/j.1095-8312.2007.00809.x

Heat, R. R., Landolt, P. J., Dueben, B. D., Murphy, R. E., and Schneider, R. E. (1992). Identification of male cabbage looper sex pheromone attractive to females. J. Chem. Ecol. 18, 441-453.

Heath, R. R., Tumlinson, J. H., Leppla, N. C., McLaughlin, J. R., Dueben, B., Dundulis, E., et al. (1983). Identification of a sex pheromone produced by female velvetbean caterpillar moth. J. Chem. Ecol. 9, 645-656. doi: 10.1007/BF00990414

Hefetz, A., Wicker-Thomas, C., and Bagnères, A.-G. (2010). "Future directions in hydrocarbon research," in Insect Hydrocarbons. Biology, Biochemistry, and Chemical Ecology, eds G. J. Blomquist and A.-G. Bagnères (Cambridge: Cambridge University Press), 477-485. doi: 10.1017/CBO9780511711909.021

Hillier, N. K., and Vickers, N. J. (2004). The role of heliothine hairpencil compounds in female Heliothis virescens (Lepidoptera: Noctuidae) behavior and mate acceptance. Chem. Senses 29, 499-511. doi: 10.1093/chemse/bjh052

Howard, R. W., and Blomquist, G. J. (2005). Ecological, behavioral, and biochemical apsects of insect hydrocarbons. Annu. Rev. Entomol. 50, 371-393. doi: 10.1146/annurev.ento.50.071803.130359

Iyengar, V. K., Rossini, C., and Eisner, T. (2001). Precopulatory assessment of male quality in an arctiid moth (Uthetiesa ornatrix): hydroxydanaidal is the only criterion of choice. Behav. Ecol. Sociobiol. 49, 283-288. doi: $10.1007 / \mathrm{s} 002650000292$

Jacquin, E., Nagnan, P., and Frerot, P. (1991). Identification of hairpencil secretion from male Mamestra brassicae (L) (Lepidoptera, Noctuidae) and electroantennogram studies. J. Chem. Ecol. 17, 239-246.

Jallon, J.-M. (1984). A few chemical words exchanged by Drosophila during courtship and mating. Behav. Genet. 14, 441-478. doi: 10.1007/BF01065444

Johansson, B. G., and Jones, T. M. (2007). The role of chemical communication in mate choice. Biol. Rev. 82, 265-289. doi: 10.1111/j.1469-185X.2007.00009.x

Joron, M., and Brakefield, P. M. (2003). Captivity masks inbreeding effects on male mating success in butterflies. Nature 424, 191-194. doi: 10.1038/nature01713

Jurenka, R. (2004). "Insect pheromone biosynthesis," in The Chemistry of Pheromones and Other Semiochemicals I. Topics in Current Chemistry, Vol. 239 (Berlin; Heidelberg: Springer), 97-132. doi: 10.1007/b95450
Jurenka, R., and Subchev, M. (2000). Identification of cuticular hydrocarbons and the alkene precursor to the pheromone in hemolymph of the female Gypsy moth, Lymantria dispar. Arch. Insect. Biochem. Physiol. 43, 108-115. doi: 10.1002/(SICI)1520-6327(200003)43:3<108::AID-ARCH2>3.0.CO;2-V

Kemp, D. J., Macedonia, J. M., Ball, T. S., and Rutowski, R. L. (2008). Potential direct fitness consequences of ornament-based mate choice in a butterfly. Behav. Ecol. Sociobiol. 62, 1017-1026. doi: 10.1007/s00265-007-0529-5

Kimura, T., and Honda, H. (1999). Identification and possible functions of the hairpencil sent of the yellow peach moth, Conogethes punctiferalis (Guenee) (Lepidoptera: Pyralidae). Appl. Entomol. Zool. 34, 147-153.

Kortet, R., and Hedrick, A. (2005). The scent of dominance: female field crickets use odour to predict the outcome of male competition. Behav. Ecol. Sociobiol. 59, 77-83. doi: 10.1007/s00265-005-0011-1

Kroiss, J., Svatoš, A., and Kaltenpoth, M. (2011). Rapid identification of insect cuticular hydrocarbons using gas chromatography-ion-trap mass spectrometry. J. Chem. Ecol. 37, 420-427. doi: 10.1007/s10886-011-9933-4

Kurtovic, A., Widmer, A., and Dickson, B. J. (2007). A single class of olfactory neurons mediates behavioural responses to a Drosophila sex pheromone. Nature 446, 542-546. doi: 10.1038/nature05672

Landolt, P. J., Zack, R. S., Green, D., and Decamelo, L. (2004). Cabbage looper moths (Lepidoptera: Noctuidae) trapped with male pheromone. Fla. Entomol. 87, 294-299. doi: 10.1653/0015-4040(2004)087[0294:CLMLNT] 2.0.CO;2

Liénard, M. A., Wang, H.-L., Lassance, J.-M., and Löfstedt, C. (2014). Sex pheromone biosynthetic pathways are conserved between moths and butterfly Bicyclus anynana. Nat. Commu. 5:3957, doi: 10.1038/ncomms4957

Lloyd, S. P. (1982). Least squares quantization in PCM. IEEE Trans. Inf. Theory 28, 129-137. doi: 10.1109/TIT.1982.1056489

Martin, S., and Drijfhout, F. (2009).A review of ant cuticular hydrocarbons. J. Chem. Ecol. 35, 1151-1161. doi: 10.1007/s10886-009-9695-4

McArdle, B. H., and Anderson, M. J. (2001). Fitting multivariate models to community data: a comment on distance-based redundancy analysis. Ecology 82, 290-297. doi: 10.2307/2680104

Millar, J., McElfresh, J., Romero, C., Vila, M., Marí-Mena, N., and LopezVaamonde, C. (2010). Identification of the sex pheromone of a protected species, the spanish moon moth Graellsia isabellae. J. Chem. Ecol. 36, 923-932. doi: 10.1007/s10886-010-9831-1

Millar, J. G. (2000). Polyene hydrocarbons and epoxides: a second major class of Lepidopteran sex attractant pheromones. Annu. Rev. Entomol. 45, 575-604. doi: 10.1146/annurev.ento.45.1.575

Miyamoto, T., and Amrein, H. (2008). Suppression of male courtship by a Drosophila pheromone receptor. Nat. Neurosci. 11, 874-876. doi: 10.1038/nn.2161

Monteys, V. S., Acin, P., Rosell, G., Quero, C., Jimenez, M. A., and Guerrero, A. (2012). Moths behaving like butterflies. Evolutionary loss of long range attractant pheromones in castniid moths: a Paysandisia archon model. PLoS ONE 7:e29282. doi: 10.1371/journal.pone.0029282

Moore, P. J., Reagan-Wallin, N. L., Haynes, K. F., and Moore, A. J. (1997). Odour conveys status on cockroaches. Nature 389, 25.

Mustaparta, H. (1996). "Olfactory coding mechanisms for pheromone and interspecific signal information in related moth species," in Insect Pheromone Research: New Directions, eds R. T. Cardé and A. K. Minks (London: Chapman and Hall), 144-163.

Myers, J. (1972). Pheromones and courtship behavior in butterflies. Am. Zool. 12, 545-551.

Nash, D. R., Als, T. D., Maile, R., Jones, G. R., and Boomsma, J. J. (2008). A mosaic of chemical coevolution in a large blue butterfly. Science 319, 88-90. doi: $10.1126 /$ science. 1149180

Nieberding, C., de Vos, H., Schneider, M. V., Lassance, J.-M., Estramil, N., Andersson, J., et al. (2008). The male sex pheromone of the butterfly Bicyclus anynana: towards an evolutionary analysis. Plos ONE 3:e2751. doi: 10.1371/journal.pone.0002751

Nieberding, C., Fischer, K., Saastamoinen, M., Allen, C. E., Wallin, E. A., Hedenstrom, E., et al. (2012). Cracking the olfactory code of a butterfly: the scent of ageing. Ecol. Lett. 15, 415-424. doi: 10.1111/j.1461-0248.2012. 01748.x

Nishida, R., Baker, T. C., and Roelofs, W. L. (1982). Hairpencil pheromone components of male oriental fruit moths, Grapholita molesta (Lepidoptera, Tortricidae). J. Chem. Ecol. 8, 947-959. 
Nishida, R., Schulz, S., Kim, C.S., Fukami, H., Kuwahara, Y., Honda, K., et al. (1996). Male sex pheromone of a giant danaine butterfly, Idea leuconoe. J. Chem. Ecol. 22, 949-972.

Ômura, H., and Honda, K. (2005). Chemical composition of volatile substances from adults of the swallotail, Papilio polytes (Lepidoptera: Papilionidae). Appl. Entomol. Zool. 40, 421-427. doi: 10.1303/aez.2005.421

Phelan, P. L., Silk, P. J., Northcott, C. J., Tan, S. H., and Baker, T. C. (1986). Chemical identification and behavioral characterization of male wing pheromone of Ephestia elutella (Pyralidae). J. Chem. Ecol. 12, 135-146.

Piskorski, R., Trematerra, P., and Dorn, S. (2010). Cuticular hydrocarbon profiles of codling moth larvae, Cydia pomonella (Lepidoptera: Tortricidae), reflect those of their host plant species. Biol. J. Linn. Soc. 101, 376-384. doi: 10.1111/j.10958312.2010.01511.x

Pliske, T. E., and Eisner, T. (1969). Sex pheromone of queen butterfly: biology. Science 164, 1169-1170.

Rantala, M. J., Jokinen, I., Kortet, R., Vainikka, A., and Suhonen, J. (2002). Do pheromones reveal immunocompetence? Proc. Roy. Soc. Lond. B Biol. Sci. 269, 1681-1685. doi: 10.1098/rspb.2002.2056

Rantala, M. J., and Kortet, R. (2004). Male dominance and immunocompetence in a field cricket. Behav. Ecol. 15, 187-191. doi: 10.1093/beheco/arg103

Rantala, M. J., Kortet, R., and Vainikka (2003). The role of juvenile hormone in immune function and pheromone production trade-offs: a test of the immunocompetence handicap principle. Proc. R. Soc. Lond. B Biol. Sci. 270, 2257-2261. doi: 10.1098/rspb.2003.2472

Robertson, K. A., and Monteiro, A. (2005). Female Bicyclus anynana butterflies choose males on the basis of their dorsal UV-reflective eyespot pupils. Proc. $R$. Soc. B Biol. Sci. 272, 1541-1546. doi: 10.1098/rspb.2005.3142

Sappington, T. W., and Taylor, O. R. (1990a). Developmental and environmental sources of pheromone variation in Colias eurytheme butterflies. J. Chem. Ecol. $16,2771-2786$

Sappington, T. W., and Taylor, O. R. (1990b). Genetic sources of pheromone variation in Colias eurytheme butterflies. J. Chem. Ecol. 16, 2755-2770.

Sappington, T. W., and Taylor, O. R. (1990c). Disruptive sexual selection in Colias eurytheme butterflies. Proc. Natl. Acad. Sci. U.S.A. 87, 6132-6135

Sasaerila, Y., Gries, R., Gries, G., Khaskin, G., King, S., Takács, S., et al. (2003). Sex pheromone components of male Tirathaba mundella (Lepidoptera: Pyralidae). Chemoecology 13, 89-93. doi: 10.1007/s00049-003-0233-5

Schulz, S., and Nishida, R. (1996). The pheromone system of the male danaine butterfly, Idea leuconoe. Bioorg. Med. Chem. 4, 341-349. doi: 10.1016/09680896(96)00011-9

Svensson, M. (1996). Sexual selection in moths: the role of chemical communication. Biol. Rev. Camb. Philos. Soc. 71, 113-135. doi: 10.1111/j.1469185X.1996.tb00743.x

Taylor, O. R. (1973). Reproductive isolation in Colias eurytheme and Colias philodice (Lepidoptera, Pieridae): use of olfaction in mate selection. Ann. Entomol. Soc. Am. 66, 621-626.

Teal, P. E. A., and Tumlinson, J. H. (1989). Isolation, identification, and biosynthesis of compounds produced by male hairpencil glands of Heliothis virescens (F) (Lepidoptera, Noctuidae). J. Chem. Ecol. 15, 413-427.

Thibout, E., Ferary, S., and Auger, J. (1994). Nature and role of the sexual pheromones emitted by males of Acrolepiopsis assectella. J. Chem. Ecol. 20, 1571-1581. doi: 10.1007/BF02059881

Thistle, R., Cameron, P., Ghorayshi, A., Dennison, L., and Scott, K. (2012). Contact chemoreceptors mediate male-male repulsion and male-female attraction during Drosophila courtship. Cell. 149, 1140-1151. doi: 10.1016/j.cell.2012. 03.045

Thom, C., Gilley, D. C., Hooper, J., and Esch, H. E. (2007). The scent of the waggle dance. PLoS Biol. 5:e228. doi: 10.1371/journal.pbio.0050228

Thomas, M., and Simmons, L. (2009). Sexual selection on cuticular hydrocarbons in the Australian field cricket, Teleogryllus oceanicus. BMC Evol. Biol. 9:162. doi: 10.1186/1471-2148-9-162

Tregenza, T. O. M., and Wedell, N. (1997). Definitive evidence for cuticular pheromones in a cricket. Anim. Behav. 54, 979-984. doi: 10.1006/anbe.1997. 0500

Van Bergen, E., Brakefield, P. M., Heuskin, S., Zwaan, B. J., and Nieberding, C. M. (2013). The scent of inbreeding: male sex pheromones betray inbred males. Proc. R. Soc. B Biol. Sci. 280, 20130102. doi: 10.1098/rspb.20 13.0102

VaneWright, R. I., and Boppre, M. (1993). Visual and chemical signaling in butterflies: functional and phylogenetic perspectives. Philos. Trans. R. Soc. Lond. B Biol. Sci. 340, 197-205.

Ward, J. H. Jr. (1963). Hierarchical grouping to optimize an objective function. J. Am. Stat. Assoc. 48, 236-244. doi: 10.1080/01621459.1963.10 500845

Westerman, E. L., and Monteiro, A. (2013). Odour influences whether females learn to prefer or to avoid wing patterns of male butterflies. Anim. Behav. 86, 1139-1145. doi: 10.1016/j.anbehav.2013.09.002

Wyatt, T. D. (2003). Pheromones and Animal Behaviour. New York, NY: Cambridge University Press. doi: 10.1017/CBO9780511615061

Wyatt, T. D. (2009). Fifty years of pheromones. Nature 457, 262-263. doi: $10.1038 / 457262 \mathrm{a}$

Xiao, W., Matsuyama, S., Ando, T., Millar, J. G., and Honda, H. (2012). Unsaturated cuticular hydrocarbons synergize responses to sex attractant pheromone in the yellow peach moth, Conogethes punctiferalis. J. Chem. Ecol. 38, 1143-1150. doi: 10.1007/s10886-012-0176-9

Yew, J. Y., Dreisewerd, K., Luftmann, H., Müthing, J., Pohlentz, G., and Kravitz, E. A. (2009). A new male sex pheromone and novel cuticular cues for chemical communication in Drosophila. Curr. Biol. 19, 1245-1254. doi: 10.1016/j.cub.2009.06.037

Conflict of Interest Statement: The authors declare that the research was conducted in the absence of any commercial or financial relationships that could be construed as a potential conflict of interest.

Received: 02 April 2014; accepted: 25 June 2014; published online: 17 July 2014. Citation: Heuskin S, Vanderplanck M, Bacquet P, Holveck M-J, Kaltenpoth M, Engl T, Pels C, Taverne C, Lognay G and Nieberding CM (2014) The composition of cuticular compounds indicates body parts, sex and age in the model butterfly Bicyclus anynana (Lepidoptera). Front. Ecol. Evol. 2:37. doi: 10.3389/fevo.2014.00037

This article was submitted to Chemical Ecology, a section of the journal Frontiers in Ecology and Evolution.

Copyright (C) 2014 Heuskin, Vanderplanck, Bacquet, Holveck, Kaltenpoth, Engl, Pels, Taverne, Lognay and Nieberding. This is an open-access article distributed under the terms of the Creative Commons Attribution License (CC BY). The use, distribution or reproduction in other forums is permitted, provided the original author(s) or licensor are credited and that the original publication in this journal is cited, in accordance with accepted academic practice. No use, distribution or reproduction is permitted which does not comply with these terms. 